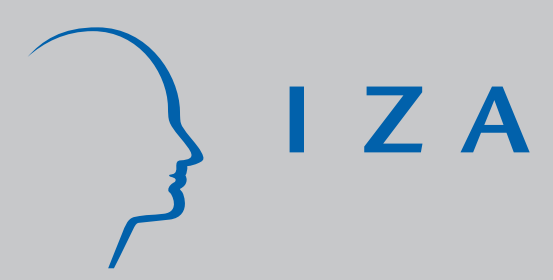

IZA DP No. 5871

Informal Workers Across Europe:

Evidence from 30 Countries

Mihails Hazans

July 2011 


\title{
Informal Workers across Europe: Evidence from 30 Countries
}

\author{
Mihails Hazans \\ University of Latvia \\ and IZA
}

\section{Discussion Paper No. 5871}

July 2011

IZA

P.O. Box 7240

53072 Bonn

Germany

Phone: +49-228-3894-0

Fax: +49-228-3894-180

E-mail: iza@iza.org

Any opinions expressed here are those of the author(s) and not those of IZA. Research published in this series may include views on policy, but the institute itself takes no institutional policy positions.

The Institute for the Study of Labor (IZA) in Bonn is a local and virtual international research center and a place of communication between science, politics and business. IZA is an independent nonprofit organization supported by Deutsche Post Foundation. The center is associated with the University of Bonn and offers a stimulating research environment through its international network, workshops and conferences, data service, project support, research visits and doctoral program. IZA engages in (i) original and internationally competitive research in all fields of labor economics, (ii) development of policy concepts, and (iii) dissemination of research results and concepts to the interested public.

IZA Discussion Papers often represent preliminary work and are circulated to encourage discussion. Citation of such a paper should account for its provisional character. A revised version may be available directly from the author. 


\section{ABSTRACT \\ Informal Workers across Europe: Evidence from 30 Countries}

The European Social Survey data are used to analyze informal employment at the main job in 30 countries. Overall, informality decreases from South to West to East to North. However, dependent work without contract is more prevalent in Eastern Europe than in the West, except for Ireland, the UK and Austria. Between 2004 and 2009, no cases found when unemployment and dependent informality rates in a country went up together, suggesting that work without contract is pro-cyclical in Europe. Dependent informality rate is inversely related to skills (measured by either schooling or occupation). The low-educated, the young (especially students), the elderly, and persons with disabilities are more likely to work informally, other things equal. In Southern and Western Europe, immigrants from CEE and FSU feature the highest dependent informality rate, whilst in Eastern Europe this group is second after minorities without immigrant background. In Eastern, Southern and part of Western Europe, immigrants not covered by EU free mobility provisions are more likely to work without contracts than otherwise similar natives. We provide evidence that exclusion and discrimination play important role in pushing employees into informality, whilst this seems not to be the case for informal self-employed. Both on average and after controlling for a rich set of individual characteristics, informal employees in all parts of Europe are having the largest financial difficulties among all categories of employed population (yet they fare much better than the unemployed and discouraged), whilst informal self-employed are at least as well off as formal employees.

JEL Classification: J21, J24, J61, J71, O17, 052

Keywords: informal employment, human capital, discrimination, minorities, immigrants

Corresponding author:

Mihails Hazans

Faculty of Economics and Management

University of Latvia

Aspazijas Blvd 5

Riga LV-1050

Latvia

E-mail:mihazan@lanet.Iv

\footnotetext{
* This paper is based on a background study (Hazans 2011a) for In from the Shadow: Integrating Europe's Informal Labor, a World Bank regional report on the informal sector in Central, Southern Europe and the Baltic countries (Task number P112988). The paper has greatly benefited from discussions with and suggestions by Truman Packard. I thank Alexander Tarvid for excellent research assistance. I thank Hartmut Lehmann, Jan Rutkowski, Indhira Santos and participants of IZA/World Bank Workshop Institutions and Informal Employment in Emerging and Transition Economies (Bonn, June 2011) for useful comments and suggestions. The usual disclaimer applies.
} 
IZA Discussion Paper No. 5871

July 2011

\section{NON-TECHNICAL SUMMARY}

The European Social Survey data covering 30 countries for the period between 2004 and 2009 are used to look at workers whose main job is informal: employees without contracts, own-account workers (except engineers, doctors, teachers, lawyers and other professionals), employers with five or less employees, and those helping in family business. On average, one out of six employed persons in Europe has been holding an informal main job during the surveys conducted in 2008-2009. This informality rate was about $11 \%$ in Nordic countries, $15 \%$ in the East, $16 \%$ in the West and $28 \%$ in the South. Among employees, the highest proportions of workers without contracts are found in Cyprus (nearly half), Israel and Greece (one third), Ireland (more than a quarter), the United Kingdom (12\%), Portugal (11\%), Ukraine, Slovenia, Bulgaria and Russia (9\% to 7\%), Romania, Spain and Poland (6\%). In addition, during the growth period of 2005-2007, significant informality rates were found in Austria (10\%), Denmark (9\%), Latvia (7\% to $9 \%$ ) and Lithuania (7\%), according to ESS and other data. Between 2004 and 2009, no cases found when the rates of unemployment and dependent work without contract in a country went up together. In all parts of Europe, the share of employees without contracts is inversely related to skills (measured by either schooling or occupation). The low-educated, the young (especially students), the elderly, and persons with disabilities are more likely to work informally, other things equal. In Southern and Western Europe, employees from Central and Eastern Europe and former Soviet Union feature the highest informality rate, whilst in Eastern Europe this role belongs to ethnic minorities without immigrant background. In Eastern, Southern and part of Western Europe, immigrants not covered by EU free mobility provisions are more likely to work without contracts than otherwise similar natives. We provide evidence that exclusion and discrimination play important role in pushing employees into informality, whilst this seems not to be the case for informal self-employed. Both on average and after controlling for a rich set of individual characteristics, informal employees in all parts of Europe are having the largest financial difficulties among all categories of employed population (yet they fare much better than the unemployed and discouraged), whilst informal self-employed are at least as well off as formal employees. 


\section{Introduction}

Paid work without legal contract is a phenomenon closely related to such fields of economic and social studies as shadow economy, tax evasion, trust in and efficiency of institutions, labor demand and labor supply, self-employment, worker mobility, labor market flexibility, social exclusion, social security, and many others. Understanding determinants of the size of informal workforce is thus important both for policy making and for design of institutional reforms. Yet research in this field, especially in European context, has been limited due to lack of comparable data.

In this paper we compare the prevalence of informal employment in 30 European countries using data from the European Social Survey (2004-2009), further referred to as ESS. Our analysis excludes under-declared work (envelope wages) and does not distinguish declared and undeclared output. In other words, we focus on dependent workers without contracts, as well as on self-employed (a further classification of self-employed into 'formal' and 'informal' will be suggested below).

We address the following questions:

- How strongly do European countries, as well as Northern, Western, Eastern and Southern Europe $^{1}$ differ from each other in terms of levels of informal employment observed in the first decade of the $21^{\text {st }}$ century? Does a stable ranking emerge?

- How does prevalence of work without contract among wage earners depend on their human capital and other characteristics? In particular, how do minorities, first and second generation immigrants compare to native workers?

- Is informal wage employment found only in small establishments in selected sectors, or is it more common?

- How are the levels of informal employment related to the economic cycle? In particular, how did they respond to the current crisis?

- Does a typical informal worker come from a poorer household than his/her counterpart who has an employment contract? What about informal self-employed?

- What are the main determinants of informal employment at the individual level? Do these determinants differ across country groups?

ESS data have some features important for the analysis of informality which are, to our best knowledge, not available in other multi-country datasets (in particular, in EU LFS). First, ESS questionnaires for rounds 2, 3, and 4 (implemented in years 2004-2005, 2006-2007, and 2008-2009, respectively) allow users to identify employees working without a contract. By contrast, LFS data (both the anonymised data sets disseminated by Eurostat and, for most countries, also the original datasets) allow users only to distinguish between permanent and temporary contracts, while answer

\footnotetext{
${ }^{1}$ We will sometimes refer to these geographical areas as to „European regions”. Otherwise (i.e. when „European” is not added) „regions” stand for within-country regions.
} 
'no contract' is not offered to respondents (like it was in round 1 of ESS) ${ }^{2}$. Comparison of ESS data of rounds 2-4 with those of round 1 suggests strongly that if the answer 'no contract' is not included, the proportion of employees who do not answer the question about type of contract (or choose answer "Don’t know") cannot, in general, be used as a proxy for proportion of informally employed dependent workers (see Table A2 in the Annex).

Second, in ESS data, a distinction can be made between self-employed persons with and without employees, and in the former case the number of employees is reported as well. This is important because in many studies which use data without direct information on contract, employees are 'assigned' to informal sector if they work in enterprises with 5 or fewer workers. It would then make sense to apply the same criterion to employers, i.e. to consider an employer with 5 or fewer employees to be working in informal sector. However, LFS and most other internationally comparable datasets provide, at best, only information on "number of persons working in the local unit" of respondent's main job; in case of employers this of course cannot be considered as a proxy for the total number of employees working for him.

Third, ESS data are available not only for all EU countries, but also for Norway, Switzerland, Russia, Ukraine, and Israel (for various data-related reasons our analysis omits Luxembourg, Malta, Turkey, and Croatia).

The contribution of the paper to the literature on informal employment is three-fold. First, we use direct survey evidence (rather than proxies) to provide a multi-country longitudinal analysis of the levels, dynamics and profile of dependent employment without contract, as well as informal selfemployment, in Europe. Importance of using direct evidence is highlighted in Henley et al. (2006), who find that "definitions of informality based on occupation and employer size seem the most arbitrary in practice”, and in Perry et al. (2007), who report (based on a survey conducted in 9 countries in Latin America) that "large firms... have a significant number of employees without social security contributions”. On the other hand, we are able to draw the line between informal and formal self-employment more accurately than most other studies (which often consider all self-employed informal). ${ }^{3}$ Importantly, for 25 countries, our analysis includes the early stage of the economic crisis of 2008-2010: field work of the round 4 of the ESS has been completely or mostly performed in 2008/q4 for 14 countries, and in 2009 for 11 countries in our sample. We provide evidence that exclusion, lack

\footnotetext{
${ }^{2}$ Moreover, in cases when the original questionnaire includes the „no contract” option, Eurostat groups these responses together with ,temporary”, making it very difficult to distinguish informally employed from who is legally employed fixed-term workers.

3 ILO (2002) states that ,the self-employed ...include high-end professionals and employers of registered enterprises, who are not considered to be informally employed. These categories are assumed to be small worldwide...”. We consider a self-employed person belonging to formal sector if he/she either works in a professional occupation (like lawyer, doctor, consultant, etc.) or has more than five employees. This approach is similar to the one found in Henley et al. (2006) and consistent with the ILO (2003) guidelines requiring that "The enterprise of informal employers must fulfill one or both of the following criteria: size of unit below a specified level of employment, and non-registration of the enterprise or its employees". We show further (see Table 3) that in Eastern Europe formal self-employed account for about 2\% or labor force, whilst in the rest of Europe this proportion is $3 \%$ and thus cannot be claimed negligible.
} 
of human capital and discrimination play important role in pushing employees into informality, whilst this seems not to be the case for informal self-employed.

Second, we show that both on average and after controlling for a rich set of individual characteristics, informal employees in all parts of Europe are having the largest financial difficulties among all categories of employed population (yet they fare much better than the unemployed and discouraged), whilst informal self-employed are at least as well off as formal employees.

Third, we present analysis of determinants of work without a contract among employees, highlighting the role of educational attainment, age and immigrant background. The results also suggest a substantial within-country regional variation in informality across Europe, except for Nordic countries, Hungary, Romania and Slovenia.

The rest of the paper is organized as follows. Section 1 briefly outlines the predictions of search and matching labor market model (Pissarides 2000) with regards to workers' sorting between formal and informal jobs. Section 2 describes prevalence and dynamics of informal employment in Europe. Section 3 compares profiles of informal and formal employees, as well as informal self-employed in terms of exclusion factors, such as long-term unemployment experience and perceived discrimination. Section 4 household income (Section 3.3). Section 5 presents econometric analysis of individual level determinants of work without contract among employees ${ }^{4}$. Section 6 concludes. Annex provides additional material related to measurement issues (including comparisons with other sources).

\section{Theoretical framework}

The literature provides several models describing the behavior or workers and firms, as well as the role of institutions and other macro factors in an economy with formal and informal sector ${ }^{5}$ in presence of labor market frictions Boeri and Garibaldi (2005); Boeri et al. (2011), De Paula and Scheinkman (2011), Basu et al. (2011) and Johasson (2011) among others assumed workers to differ just in one parameter (skill or labor market productivity); they predict that informal jobs are occupied by relatively low skilled workers. Our approach here is closer to that of Bosch and Maloney (2010), where workers have several attributes affecting their comparative advantage in one of the sectors, as well as search intensity. Our focus is on workers, whilst macro factors and institutions are considered exogenous ${ }^{6}$. Compared to Bosch and Maloney (2010), we provide a more detailed and structured description of workers' attributes and derive specific predictions with respect to determinants of informality.

\footnotetext{
${ }^{4}$ See Hazans (2011b) for a more general analysis of determinants of labor market status, including employment formality.

${ }^{5}$ Unemployment is considered either as an option within each of the two sectors or as a "third sector”.

${ }^{6}$ See Hazans (2011c) for a more general approach. In a general equilibrium framework, Boeri and Garibaldi (2005) derive effects of some institutions; Basu et al. (2011) derive an 'optimal' minimum wage level.
} 
Following Bosch and Maloney (2010), we do not explicitly model firms' behavior, treating demand for formal and informal labor as exogenous (yet allowing for regional heterogeneity). However, in the context of search and frictions model, we assume that firms try to minimize recruitment costs; thus, to fill an informal job they target individuals belonging to specific groups known to known to be over-represented in the informal sector and/or to have difficulties in the formal labor market; in addition they might use networks of their existing informal employees. This way, "informal” social capital increases individual's chances to receive an informal job offer. Likewise, "formal" social capital raises chances to receive a formal job offer.

At a given moment of time, utility of an individual $i$ (from region $R$ ) from choosing any of available labor market states $s$ (formal and informal dependent employment, formal and informal selfemployment, unemployment and inactivity) is given by

$$
U_{i s}=u_{s}\left(V_{i}\right)+\delta_{R s}+\varepsilon_{i s}, V_{i}=\boldsymbol{x}_{i} \boldsymbol{\beta}_{s}+\mathbf{z} \gamma_{s},
$$

where $V$ is the expected present value of the best of the vacancies (including the present job if any) available for the agent in the state $s, \boldsymbol{\beta}_{s}$ and $\gamma_{s}$ are state-specific returns to [vectors of] individual characteristics $\boldsymbol{x}_{i}$ and macro factors $\boldsymbol{z}, u_{s}$ are given utility functions, and $\delta_{R s}, \varepsilon_{i s}$ are region and individual level random errors. In the random utility maximization framework (McFadden, 1981), an agent chooses the state in which $U_{i s}$ is maximal. Formal dependent work might not be available to the most low-skilled workers, because formality is costly to the firms, and it does not pay to employ a low-productivity worker formally. This and other basic features of informal and formal jobs, along with the targeted recruitment process outlined above, suggest the following list of main individual determinants of informal (rather than formal) dependent employment (conditional on being an employee $)^{7}$ :

(i) low skills (as measured by educational attainment, occupation, experience, etc.) and/or low unobserved productivity;

(ii) strong preference for flexible working time and/or substantial volatility of desired working hours over the course of the year;

(iii) low value placed on job security;

(iv) large endowment of social capital relevant for the informal sector (belonging to a group or groups which is known to be over-represented in the informal sector and/or to have difficulties in the formal labor market: ethnic or linguistic minority, first or second generation immigrants, students, pensioners, persons with disabilities);

(v) low level of tax morale and/or trust in state institutions.

Apart from the standard prediction that informal workers are likely to be less skilled, it follows that the age-informality profile is likely to be U-shaped. Indeed, younger and older workers are usually less productive than middle-aged ones and less prepared for a stable fulltime work; the young ones, especially students, and those in retirement age are also less concerned about job stability. Students and persons with disabilities, also are more likely than others to receive informal job offers

\footnotetext{
${ }^{7}$ See Hazans (2011b) for econometric analysis of agents' sorting across all six labor market states.
} 
(and, plausibly, to be less productive) than other workers, so we expect these groups to feature higher informality rates, other things equal.

Minorities, workers with immigrant background, as well as workers in less developed regions, are more likely to hold informal jobs because of large informal social capital which, in addition, might interact with low trust in institutions and in some cases with productivity problems caused by insufficient language skills.

With respect to gender and family status, the predictions are ambiguous because those whose family status suggests a strong preference towards flexible working time, are also likely to place high value on job security and be more risk averse in general.

\section{Prevalence and dynamics of informal employment in Europe, 2004-2009}

In this section we use the ESS data to compare prevalence of informal employment (in the main job) across 30 European countries and years 2004 to 2009. For 25 countries we will also show (in Table A3) that ESS-based results for 2004-2006 are well in line with the results of the Fourth European Working Conditions Survey (EWCS) conducted in 2005/Q4 (see European Foundation for the Improvement of Living and Working Conditions, 2007); it is worth noting that ESS and EWCS have been coordinated by different research teams, and the fieldwork providers for the two studies have been also different in all but three countries. For few countries, we will also provide comparisons with other studies which give information on work without contract.

\subsection{Measuring informal employment}

Although international guidelines for a statistical definition of informal employment have been developed by ILO (see ILO, 2002; ILO, 2003; Hussmanns, 2004), the literature suggests a variety of approaches to identifying informal working relationships using, 'legalistic', 'de facto', or 'productive' definitions (see e.g. Henley et al., 2006; Perry et al., 2007; Bernabè, 2008; OECD, 2009; PfauEffinger, 2009). Legalistic definitions refer (in the simplest cases) to social security contributions or to employment status (self-employment vs. dependent employment) and, in the latter case, to employment contract. De facto ('in law or in practice') definitions take into account various situations when labor regulations are not applied, not enforced, or not complied with for any reason. Productive definitions rely on characteristics of the employer and/or the employed, e.g. size of establishment or occupation of a self-employed person. Combinations of these approaches are common; the ILO guidelines distinguish nine categories (cells) within informal employment (see ILO, 2003 or Hussmanns, 2004 for details).

One can further distinguish informal employment at the main or secondary job. Moreover, the concept of informal employment overlaps with the concept of under-declared work (also known as 
'envelope wages' or 'quasi-formal employment', see Riedmann and Fischer, 2008; Williams and Renooy, 2008; Williams, 2009) ${ }^{8}$. Arguably, such quasi-formal employment falls into ILO (2003) definition of "informal employment outside the informal sector"; however, ILO (2003) asserts that "for purposes of analysis and policy-making, it may be useful to disaggregate the different types of informal jobs", and work without a contract is clearly a category which deserves to be analyzed separately. Hereafter, as far as employees are concerned, we apply the term 'informal employment' only to work without a contract.

To identify informal employees, different surveys use either direct questions about employment contract/'labor card'/‘tax book’ or indirect questions (e.g. about social security contributions, paid annual leave or sick leave), see e.g. Hussmanns (2004), Henley et al. (2006), Perry et al. (2007), Bernabè (2008). Although, as shown by Henley et al. (2006), different definitions of informal employment may lead to substantially different results and "may imply very different conceptual understandings of informality”, exact definitions applied in particular studies are often dictated by data availability. To give an example, Bernabè (2008) suggests a classification of informal employment, but operational definitions based on available household surveys for seven CIS countries appear to be far from identical. For cross-country studies, ability to apply a comparable operational definition is crucial. This study fills an apparent gap in the literature in this respect for Europe.

Details of our suggested classification of the employed population by 'formality' of employment are given in Table 1. The ESS questionnaire does not ask details on work activities other than main job, hence informal employment outside main job is beyond the scope of this study. Hence, our estimates of informality rates are quite conservative. Formal employment includes anybody holding an employment contract (including family workers with a contract).

Employers with more than five employees, as well as the self-employed without workers who work as professionals (i.e. those belonging to ISCO main group 2) are considered formally selfemployed. The "five workers threshold" is a natural extension of the approach used in the literature when classifying the "formality" of employees based on data without information on contract type. On the other hand, professionals are more often operating legally with some kind of license and pay taxes from at least some part of their income; unreported part of their income, if any, if not relevant for our classification - as are 'envelope wage’ payments received by legally employed workers. Other selfemployed persons (i.e. all non-professional self-employed operating solely, as well as employers with 5 or fewer workers) are considered informally self-employed. Thus, all employers, including those working as professionals, are treated according to the firm-size criterion ${ }^{9}$.

\footnotetext{
8 There are also broader, activity-based, concepts of undeclared work and shadow economy activities (Pedersen, 2003; Djankov et al., 2003; Hanousek and Palda, 2003; Schneider, 2005; Williams and Renooy, 2008; Williams, 2009; Feld and Schneider, 2010; Schneider et al. 2010) which are not considered in this paper.

${ }^{9}$ An alternative approach would be to classify all employers working as professionals as formally self-employed, disregarding the number of employees. In both cases some classification errors are inevitable. As a robustness check, informality rates have been recalculated under this alternative definition. Country rankings are not affected on total informality and not significantly affected on informal self employment. The decline in the share of informal self employed in the extended labor force in most cases is well below 1 percentage point, except for Italy, Germany, Switzerland and Cyprus where it is between 1.0 and 1.3 points (from a base above 10\%). In
} 
Persons working without a contract for own family's business (family workers) form a separate (small) category. These persons belong rather to informal than to formal employment (ILO, 2003), but being residual earners from profits they are different from both the formal employees and the selfemployed. Finally, employees without a contract (or those uncertain of their contract) are informally employed, i.e. belong to informal dependent employment.

Note that there are some differences across countries in the legal requirements on employment contracts for dependent workers (see Table A1 in the Annex). In Eastern European countries (except Hungary and Poland), in Nordic countries (except Finland), as well as in Switzerland, Italy and Greece, a written employment contract is always required. In most of these countries the contract must be signed in advance or immediately after starting work; in Russia and Ukraine - within 3 days; and in Greece - within 2 months.

By contrast, in most of the Western Europe, as well as in Hungary, Poland, and Portugal, having a written contract is considered good practice but is required either only for "atypical” (apprenticeship; fixed-term; seasonal; part-time; replacement, etc.) employment, as in Austria, Belgium, France and Portugal, or, the other way around, only for contracts of indefinite duration (Hungary and Cyprus), or is not generally required (Poland, Finland, Germany, the Netherlands, Ireland and the UK) ${ }^{10}$. In all these cases a contract as such is required but it might be oral (in Finland - also electronic); moreover, the employee must be given written terms of employment (ToE) signed by the employer (the mandatory content of ToE is specified in the law).

From employee perspective, this latter document is as good as a contract - and it is fair to assume that an employee with an oral contract and a written ToE will not choose the answer "No contract" in the questionnaire (it is important to emphasize that ESS questionnaire asks about a contract as such rather than about a written contract). On the other hand, workers with oral contracts who were not given written ToE might well respond as if they work without a contract, but their situation is in fact closer to informal than to formal employment. In other words, there are reasons to believe that, most of the time, the ESS contract question indeed identifies informal employees even in the countries where a written contract can be replaced by written ToE. Like with the written contracts, some countries request that ToE are issued in advance or immediately after starting work, whilst others allow for this some time: Finland, the Netherlands and Cyprus - 1 month; the UK and Ireland 2 months. In fact, during this period the employee might be considered employed informally, and the possibility to postpone signing of ToE as such is likely to increase informality (in case of inspection, the employer might say that the employee in question started to work less than a month or two ago). Whether or not this likelihood will materialize depends on other factors - institutions and social norms (including tax morale). As we will see later, four of six countries where signing the contract or ToE

relative terms, the decline is below $3 \%$ for 12 countries, between $4 \%$ and $6 \%$ for another 12 countries, $7 \%$ to $9 \%$ for 3 countries, and between $10 \%$ and $14 \%$ for Germany, Switzerland and Romania.

${ }^{10}$ In Spain, a written contract is required if either party requests it (even during the course of employment relationship), as well as for "atypical” employment. 
can be postponed substantially (Greece, Cyprus, the UK and Ireland) feature very high dependent informality rates, whilst it is not the case for Finland and the Netherlands.

In the literature, survey-based prevalence of informal employment has been presented as a percentage of (i) working-age population; (ii) labor force; (iii) total (or non-agricultural) employment; (iv) salaried workers. The choice of base depends on the definition of informality, on the information available in the survey, and on the purpose of the study. The first approach is used in studies focusing on transitions between sectors and labor market states (e.g. Bosch et al. (2007), Bosch and Maloney (2010), Nikolova et al. (2010)), as well in cases when data come from surveys where questions on shadow activities refer to a much longer period (e.g. 12 months) than the ones used in ILO definitions of employment (e.g. Riedmann and Fischer, 2008; Williams and Renooy, 2008). Loayza et al. (2009: Figure 1) apply (ii) and (iii), whilst Perry et al. (2007: Figure 2) use all four approaches. The third approach is used also by ILO (2002) and Feld and Schneider (2010: Table $14^{11}$ ). Given that unemployment and 'discouragement' are alternatives to formal or informal employment that are shaped by the same policies and economic circumstances, we argue that the labor force extended to include discouraged workers is a more reasonable base for measuring the size of informal employment, especially for the purposes of international comparisons.

To allow comparability with other studies, in Table 2 we present various measures of prevalence of informal employment in Southern, Eastern, Western, and Northern Europe. As we are mostly interested in comparisons between countries and in the effects of institutions, most of our results are either based on within-countries calculations or derived assuming that a respondent from any country is equally likely to be surveyed (i.e. countries are not weighted by population size); in Table 2, however, we present both equally-weighted and population-weighted estimates for the four above mentioned geographical areas, as well as for Europe as a whole. Equally-weighted estimates (means shown in Table 2 and medians found e.g. in Figure 2) refer to prevalence of informal employment in 'an average country' in a country group; in this case the size of country's population does not affect the estimate - Belgium has the same weight as Germany. Population-weighted estimates refer to the share of informal employment in the adult population (or labor force, or total employment) of European regions. Such estimates are of interest on their own, but being dominated by large countries they are less useful for policy analysis.

\subsection{Informal employment in Eastern, Western, Northern and Southern Europe}

It appears that informality is most prevalent in the South and least prevalent in the Nordic countries, whilst the difference between the West and the East is, on aggregate, surprisingly small, especially as far as population-weighted estimates are concerned. According to population-weighted estimates based on respondents' status during the survey (Table 2, panel A, left), the proportion of

\footnotetext{
${ }^{11}$ Feld and Schneider (2010) express the estimated full-time equivalent shadow labor force as percentage of 'official labor force', but the figures suggest that by labor force they mean employed population.
} 
employees without a contract among all employees in 2008-2009 varies from 2.7\% in the Nordic countries to $9.5 \%$ in the Southern Europe, whilst it is just above 5\% in the West and in the East alike; when those who did not respond to the question regarding the contract are treated as not having a contract (which is a plausible assumption), the prevalence of work without a contract becomes higher in the East (6.7\%) than in the West (5.5\%), whilst it does not change much in the North and in the South. Equally-weighted estimates are substantially higher than the population-weighted ones for the South and for the West, disregarding the treatment of non-response. This is due to very high proportions of employees without contracts in a few relatively small countries: Cyprus (almost half), Greece and Israel (about one third), Ireland (close to one fifth), and Austria (one tenth); see Table 3 for details.

Total informal employment (i.e., employees without contracts, non-professional self-employed operating solely, employers with 5 or less employees, and family workers) accounts for about $10 \%$ of extended labor force in the Northern Europe, about 14\% in the West and in the East, and about 25\% in the South; equally-weighted averages are again higher for the South and for the West (Table 2, panel A, right). The overall population-weighted average for the 30 countries covered is $15.7 \%$, and equallyweighted average is $17.4 \%$. Hence one out of six labor force members (and about one out of ten adult residents) in Europe has been working informally during the surveys conducted in 2008-2009. See Table 2 for more details.

Informal employment is often irregular or seasonal. During the periods of employment, shadow workers might become hard-to-reach by the surveyors if they work long hours or work far away from their residence. This is why, in principle, estimates based on engagement in informal work during the last 12 months (rather than during the survey week) are more reliable. In the case of ESS such an approach also helps to address the potential seasonality issue (the season of the field work varies by country, see Table 3). ESS data provide detailed information about the last job (if any) of respondents who are currently non-employed, so that those who were employed informally can be identified according to definitions in Table 1.

Unfortunately, it is not possible to apply the 12 months reference period exactly, because for each respondent we know the month of the interview but only the year of the last job. We have dealt with this as follows: respondents interviewed between September and December (respectively, between January and August) have been classified as 'recently employed informally' if they last worked (informally) within the same year (respectively, within the same or the previous year). In most countries, the core period of field work was between September and March, so that in 21 out of 30 countries the average reference period deviated from 12 by no more than 2 months; in 6 countries it was about 15 months, and only in Latvia and the Czech R. it was close to 18 months. Moreover, for each of the four European regions the average is close to 12 months: 11 months for the North, 11.6 months for the West, 12.6 months for the South, and 14.6 months for the East.

Based on these reference periods, the estimated size of currently non-employed population engaged in informal employment during the 12 months preceding the 2008-2009 round of the ESS is 
$3.5 \%$ of current extended labor force, ranging from $1.5 \%$ in the Nordic countries to $3 \%$ in the West to $4 \%$ in the East; for Southern Europe, the population-weighted estimate is 3.6\%, but the equallyweighted one reaches 5.5\% (Table 2, panel B, left). Note that the vast majority of these cases concerns dependent employment without a contract (rather than self-employment). When these estimates are added to the estimates of informal employment during the survey, the overall population-weighted (respectively, un-weighted) average estimate of population recently engaged in informal employment for the 30 countries covered is $19.2 \%$ (respectively, 21.3\%) of the current extended labor force, or $11.4 \%$ (respectively, 12.8\%) of the population aged $15+$. The informality ranking of the four European regions remains unchanged: the highest prevalence of informal employment is found in the South (more than one quarter of extended labor force); in the West and in the East this proportion is one sixth, whilst in the Nordic countries it is between one ninth and one eighths (Table 2, panel B, right). Note these are lower bound estimates, because respondents employed during the survey were not asked about their past activities.

Figure A1 (in the Annex), based on the results of rounds 2 to 4 of ESS, amended with (comparable and available for all EU members) results from the Fourth European Working Conditions Survey (2005/Q4), summarizes main findings on the prevalence of informal employment in the four European regions for the whole period between 2004 and 2009 (like in all Figures hereafter, countries in Figure A1 are not weighted by population size). Overall size of informal employment decreases from the South to West to East to North, but the median prevalence of dependent informal employment is higher in the East than in the West. For each of these country groups, the median (across space and time) level of informal self-employment is higher than that of informal dependent employment. The East and the North are much more homogeneous in terms of informal employment than the West and the South.

\subsection{Country level estimates}

Table 3 presents breakdown of extended labor force by proximity to formal employment for each of 30 European countries as of 2008-2009 (data for Austria and Italy refer to 2007 and 2006, respectively), along with the LFS-based unemployment rate for the respective period of field work, and the estimate of the non-employed population which was recently informally employed. Figure 1, derived from Table 3, features current total informal employment and its two components, workers without contracts and informal self-employed, measured as proportions of extended labor force; on top of this, recent informal employment of currently non-employed population is shown in the same units. Adding the 'recent' component significantly increases the estimated level of informality for a number of countries (see Figure 1 for details), but leaves the ranking basically intact. In the following discussion we refer to the current levels of informal employment, unless stated otherwise. 


\section{Share of Extended Labor Force Employed Informally 2008-2009}

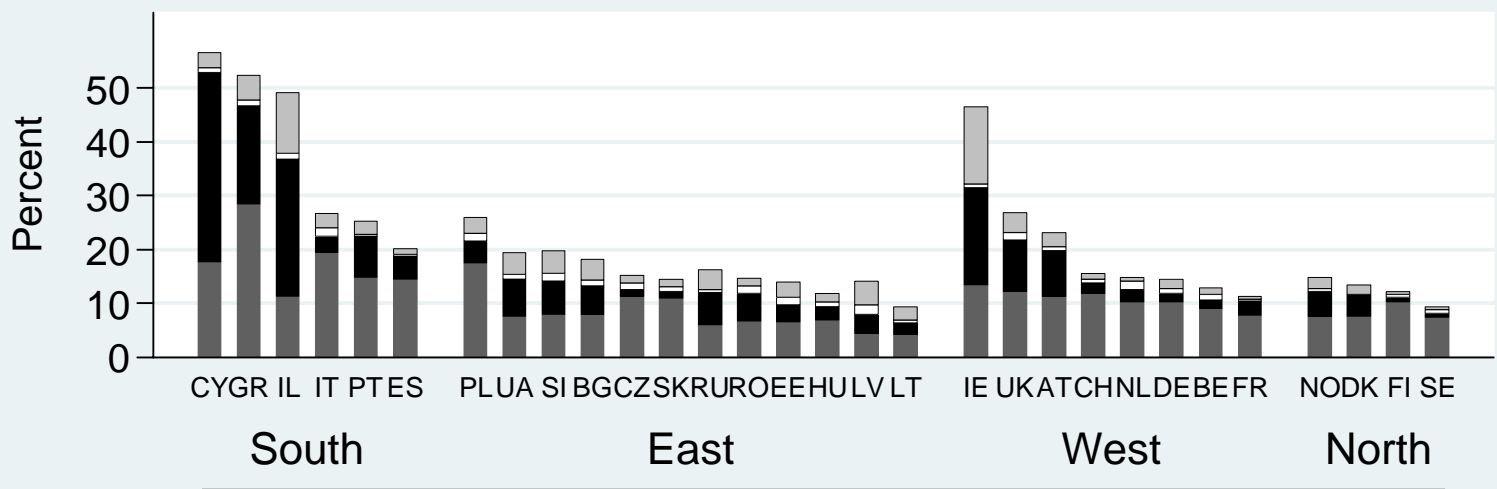

\begin{tabular}{|l}
\hline \\
$\square$ Non-employed who recently were informal employees \\
Non-employed who recently were informal self-employed \\
Informal employees \\
Informal self-employed
\end{tabular}

Labor force extended to include discouraged workers

Austrian data refer to 2007; Italian data refer to 2006

Due to data limitations, shares of non-employed who were recently informally employed

are not perfectly comparable across countries. Average 'recent' period varies as follows:

10-15 months in the South and in the West, 11-18 months in the East, 10-11 months in the North

Source: Calculation with ESS data

\section{Figure 1 Selected European countries by share of extended labor force employed informally, 2008-2009}

Notes: Informal self-employment includes all non-professional self-employed operating solely, as well as employers with 5 or fewer workers. Informal employees are those working without a contract (or those uncertain of their contract). Extended labor force includes persons which, during the reference week, were either employed or unemployed and willing to work. The latter category includes both those unemployed who were actively looking a job and those who were not actively looking for a job. See Tables 1 and 3 for details.

Source: Calculation with ESS data.

All Southern European countries appear to be heavily informal, with $37 \%$ to $53 \%$ of economically active and marginally attached population working informally in Israel, Greece, and Cyprus; in Spain, Italy and Portugal this proportion is between $19 \%$ and $22 \%{ }^{12}$. These six countries together with Ireland (33\%), the UK and Poland (22\% each), and Austria (20\%) constitute the 'highly informal” part of working Europe.

On the other extreme is Lithuania with estimated $6.4 \%$ of extended labor force working informally, followed by Latvia, Sweden, and Hungary with $8.0 \%$ to 9.4\%; Estonia, France, and Belgium feature just slightly higher level of informality around $10 \%{ }^{13}$. In other countries covered by the study (Finland, Denmark, Norway, Germany, Netherlands, Switzerland, Romania, Russia,

\footnotetext{
${ }^{12}$ Actual level of informality in the South might be even higher, as seasonal immigrant workers (e.g. fruitpickers) are mostly not covered by ESS surveys. This remark applies also to France, Germany, Ireland and UK.

${ }^{13}$ Recall that our analysis is restricted to the form of employment relationship, while envelope wages (or quasiformal employment, see Williams, 2009) are not considered; Lithuania, Latvia, Hungary, and Estonia are among the countries with relatively high prevalence of envelope wages, see Riedmann \& Fischer (2008), Williams and Renooy (2008).
} 
Slovakia, Czech R., Bulgaria, Slovenia, and Ukraine) $11 \%$ to $14 \%$ of the extended labor force are working informally.

Classifying the Baltic countries and Hungary as low-informality countries based on data referring to the time of crisis, which was much deeper in these countries than elsewhere in the EU, should be taken with care. Indeed, Latvia was among the top ten countries regarding informal dependent employment in 2007, whilst Lithuania was just outside the top 10 in terms of both dependent and total informal employment in 2005 (see Table A3). By contrast, informality rate has been always low in Hungary and, according to most estimates, in Estonia.

As a robustness check, in Table A3 we compare ESS-based proportions of employees working without contracts and proportions of all informally employed persons in total employment for 2004 2006 with similar indicators calculated from the Fourth European Working Conditions Survey ${ }^{14}$ conducted in 2005/Q4. Cyprus, Greece and Ireland, with very high rates, occupy the top three positions in informality ranking by each of the two criteria in both surveys. Top ten countries by the total prevalence of informal employment are also the same for both surveys; the list repeats the one given above for 2008-2009, excluding Israel (not represented in EWCS) and adding Bulgaria ${ }^{15}$. With regards to work without a contract, nine out of top ten countries are the same in both surveys. Moreover, for most countries the EWCS-2005 total informality rate is very close either to both ESS2004 and ESS-2006 rates or at least to one of them. Situation with the dependent informality rates is broadly similar. The exceptions in both cases include Slovenia, Norway and the Netherlands.

The coherent findings from ESS and EWCS raise concerns about the quality of field work performed in the countries of Southern Europe, as well as UK, Ireland and Poland for the Special Eurobarometer Survey on Undeclared Work in the European Union (Riedmann and Fischer (2008), according to this survey, even after adding together positive responses and non-response, the level of informal employment in these countries is significantly lower that it follows from the ESS data (detailed comparisons are available on request).

When recent informal employment is accounted for, the largest increases in the informality level are found in countries where it was already high. As the result, the total level of informal employment is [at least] around 50\% in Ireland, Israel, Greece, and Cyprus, around 25\% in Austria, the UK, Poland, Portugal, and Italy, and close to $20 \%$ in Spain, Ukraine, Slovenia, and Bulgaria. Most of the other European countries feature informality level from 14 to $16 \%$, whilst it is $11 \%$ to $13 \%$ in France, Hungary, Finland, Belgium, and Denmark, and just 9\% in Sweden and Lithuania.

In terms of relative size of dependent and self-employed informal workforce, three groups of countries emerge:

\footnotetext{
${ }^{14}$ The difference between the two surveys in handling the contract question is minor: EWCS provides answer options „A temporary employment agency contract”, „An apprenticeship or other training scheme” and „Other” (which we of course do not treat as informal); on average these account for $3.2 \%$ of all responses, although this proportion varies between $4 \%$ and $6 \%$ in six countries and between $6 \%$ and $8 \%$ in the Czech R. and Greece.

${ }^{15}$ Romania is missing from the ESS results on 2004-2006 and hence is excluded from the EWCS top ten for this comparison.
} 
(i) In Cyprus, Israel, and Ireland both groups are large, but employees without contracts dominate the informal sector (even despite seasonal migrant workers are likely to be not covered, see footnote 12);

(ii) In Russia, Ukraine, Bulgaria, Romania, Slovenia, Latvia, the United Kingdom, and Austria the two groups are of comparable size;

(iii) In remaining countries (i.e., Portugal, Spain, and Italy; the four Central European countries; Estonia and Lithuania; the Nordic countries; as well as Switzerland, Netherlands, Germany, France, and Belgium) the informal sector is dominated by the selfemployed.

The latter finding calls for a closer look, given that, according to anecdotal evidence, in countries with more restrictive Employment Protection Legislation a large share of self-employed are hired as „self-employed service providers” and doing work that is in every way identical to a formal dependent worker's. However, even if this is the case, in a survey such workers might describe their status as „an employee without a contract” or even as „an employee with a contract” (the contract being not an employment one though). Fortunately, ESS data allow to distinguish between 'true selfemployed' and 'quasi-self-employed', using the question „Are you allowed to decide how daily work is organized?" (self-assessment, where 0 means „I have no influence”, and 10 means „I have complete control”). The data do not support the hypothesis that a substantial proportion of ESS respondents which classify themselves as informal self-employed are in fact employees. Their median selfassessed autonomy is 10 in all countries but Portugal, where it is 9, and mean self-assessed autonomy in all countries is well above that of formal employees. Figure 2 shows that the same is true also for the 25th percentile of the autonomy variable, thus excluding the possibility that even a quarter of informal self-employed are in fact dependent workers.

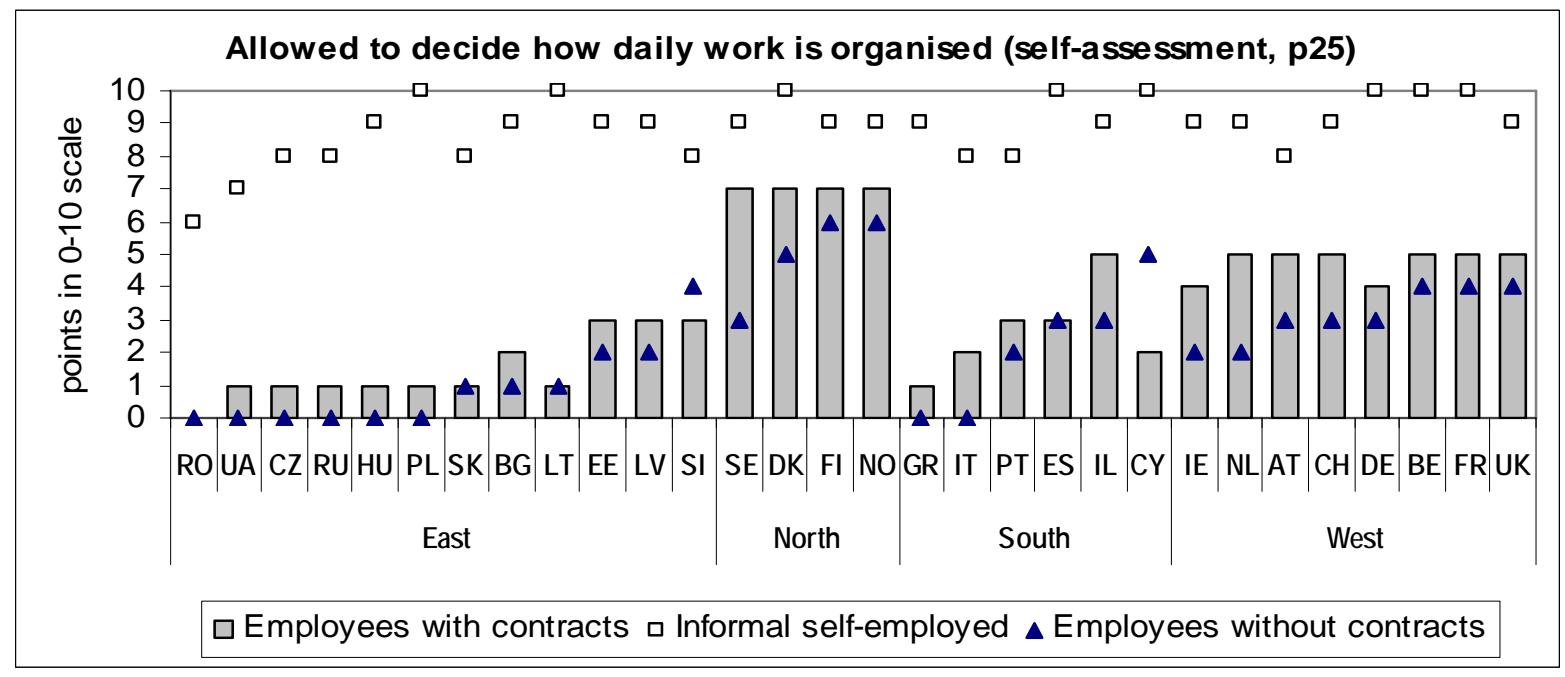

Figure 2 Worker autonomy: Informal self-employed vs. formal and informal employees. 2004-2009

Notes: The Figure displays the $25^{\text {th }}$ percentile of the self-assessed autonomy for each of the three groups. Source: Calculation with ESS data 
An important finding from Table 3 and Figure 1 is that median country in the East features a substantially higher proportion of employees without contracts than median country in the West. In fact, in 5 out of 8 Western European countries (and in 7 out of 12 countries when the Nordic countries are added) workers without contracts account to less than $3 \%$ of extended labor force, while among 12 Eastern European countries this is the case only for four countries, and the median is about $4 \%$. This provides at least some support to an 'intuitive' belief that there 'should' be more informality in the East.

\subsection{Dependent informality rates by worker and job characteristic}

Table 4 reports, for each of the four European regions and for Europe as a whole, proportion of informal employees among all employees (the dependent informality rate), broken down by gender, age, educational attainment, origin, occupation, size of establishment, and economic activity. The estimates refer to 2008-2009 and are non-weighted averages of country-specific estimates. Apart from the South as a whole, Table 4 includes a separate column for Spain, Portugal, and Greece ${ }^{16}$. It appears that in Southern Europe prevalence of work without contract is higher among females (23\% vs. 19\% among males), whilst elsewhere the difference is fairly small (larger differences exist at the country level though). Plausibly, this has to do with the fact that the share of hospitality, personal and household services (sectors which are female-dominated and feature high informality rates) in dependent employment is higher in the South than elsewhere.

In all parts of Europe, the lowest dependent informality rate is found among tertiary-educated workers, whilst the highest rate is found among medium-educated in the South and among loweducated elsewhere. Overall average is $14.5 \%$ for low-educated workers, $8.4 \%$ for medium-educated, and $5.7 \%$ for those with higher education. Likewise, the smallest proportion of workers without contract (5\% on average, ranging from $1 \%$ in the North to $17 \%$ in the South) is found among those holding highly-skilled non-manual occupation, whilst the highest informality rate is associated with elementary occupations (17\% on average, from $8 \%$ to $10 \%$ in the North and East, to $15 \%$ in the West to $30 \%$ in the South). For other occupations, the overall informality rate is about $10 \%$, ranging from $4 \%$ in the North to $6 \%$ in the East to $9 \%$ in the West to $21 \%$ in the South. To sum up, dependent informality rate is inversely related to skills (measured in terms of either schooling or occupation). These findings are in line with theoretical expectations outlined in Section 1 (see also Perry et al., 2007: pp. 6, 9; Pfau-Effinger, 2009: Table 1, among others): motivation to go informal is strongest for low-skilled, low-productive workers both on the supply side (as their alternative in the formal sector is not much better) and on the demand side (small firms find it too costly to hire formally low-productive workers), as well as with empirical findings from Latin America (e.g. Henley et al., 2006: Table 5) and Italy (Boeri and Garibaldi, 2005: Table 2).

\footnotetext{
${ }^{16}$ Recall that for Italy the latest available data refer to 2006, whilst two other Southern countries in our data, Cyprus and Israel, are small.
} 
The age-informality profile is U-shaped: The informality rate is $17 \%$ among the youth, $7 \%$ for the prime age workers, $9 \%$ for the 55-64 year olds, and 16\% among those in retirement age. In the West and (to a smaller extent) in the South, the dependent informality rate among the retirees is higher than among the young workers, whilst it is the other way around in Eastern Europe and in the Nordic countries (see Table 4 for details). Again, both supply and demand side explanations are readily available. On the demand side, both the young and the elderly are likely to be among the least demanding jobseekers, acknowledging their below-average productivity (and, in case of the young, facing above-average unemployment rates). In addition, both groups are interested in flexible work schedule which is often easier to achieve via informal employment. Young workers are likely to be less concerned with and/or less informed about social security and more willing to trade it for higher in-hand payments. For those seeking their first job, informal employment might be the most straightforward way to gaining some work experience, thus facilitating school-to-work transition. In countries with a strong apprenticeship culture (like Germany, Austria, France, and the UK), informal apprenticeships might be seen as a natural complement to the formal apprenticeship system ${ }^{17}$.

On the supply side, the low productivity factor works in the same way as in the case of loweducated workers. In addition, both the young and the elderly feature above-average quit rates, thus making firms worry about firing costs if these workers were to be hired formally. Higher informality among the elderly in the West and in the South might have to do with higher firing costs for older workers, a feature which is less pronounced or weakly enforced in the East (Muravyev, 2010).

One out of five students-employees works without a contract. Except for Southern Europe, informality among students is significantly higher than among the youth in general. In Southern and Northern Europe, informality rate substantially is well above its average level among employees affected by disability or chronic illness. These findings are consistent with the "informal" social capital story outlined in Section 1.

There is a large body of literature providing robust evidence that ethnic and language minorities face various forms of labor market disadvantages in European labor markets; see Kahanec and Zaiceva (2009) and Kahanec, Zaiceva and Zimmermann (2010) for overview; Kahanec and Zimmermann (eds.) (2011) for country studies. Ambrosini (2001) and Flaquer and Escobedo (2009) refer to the availability of a high number of immigrants without work permits as one of the reasons for relatively high share of undeclared work in Southern European countries. Say (2011) asserts that „Immigrants... may be less aware of employment protection regulations and less likely to claim their rights, which may create a gap between the costs for employers of hiring a native relative to hiring an immigrant” and finds that negative effect of a strict EPL on employment and hiring rates is less pronounced for immigrants than for natives. The same argument, however, suggests that immigrants are more likely to accept informal jobs. Table 4 supports this hypothesis, but to a different extent depending on the country group.

\footnotetext{
${ }^{17}$ I thank Truman Packard for this remark.
} 
In the South, one finds a classic divide: the dependent informality rate is $16 \%$ among native majority population, whilst it varies between $24 \%$ and $37 \%$ in all other groups: local born ethnic or linguistic minorities, second generation immigrants, as well as first generation immigrants (the highest rate is found among immigrants from CEE and former Soviet Union; in Spain, Portugal and Greece this rate exceeds 50\%). In Eastern Europe, the picture is broadly similar: local born minorities feature the highest dependent informality rate of about $11 \%$, followed by second generation immigrants and immigrants from CEE and former Soviet Union with 7\%, whilst this rate is just $4 \%$ among the natives. Moreover, in Eastern Europe, as well as in Spain, Portugal, and Israel, ethnic and linguistic minorities are more likely to work informally also after controlling for a variety of characteristics (Table 9).

In Western Europe, the only minority group with above-average proportion of non-contracted employees consists of immigrants from CEE and former Soviet Union: 12\% of employees of this origin works without contracts, whilst for the natives this rate is $7 \%$. In the Nordic countries no clear pattern emerge, probably because the sub-sample of informal immigrant employees is too small.

Table 4 also compares informality rates of immigrants depending on whether they do have an "automatic" working right due to nationality (based on country- and year-specific rules on free movement of labor within EU). The differences by legal status are smaller than those by geographic origin. Somewhat surprisingly, informality rates are slightly higher among immigrants covered by the "free movement of labor" provisions in all parts of Europe except the South. It appears that in other parts of Europe persons not covered by the provisions are either not likely to work as non-contracted employees or they are not captured by the ESS surveys. On the other hand, persons covered by the provisions are more likely to move without a job in hand, and hence more likely to end up with an informal job. The situation is strikingly different in Spain, Portugal, and Greece, where informality rate among non-covered immigrants is twice as big as among covered ones (33.7\% vs. 16.5\%). After controlling for individual characteristics and industry of employment, non-covered immigrants in Southern and Eastern Europe are more likely to work informally than natives and, in the South, also than covered immigrants (Table 9).

As expected, informality sharply declines with the size of establishment. Estimated across all 30 countries proportion of non-contracted employees is $16 \%$ in establishments with less than 10 workers, $8 \%$ in units with 10 to 24 workers, 5.5\% in units with 25 to 99 workers, and $4 \%$ in those with 100 or more workers. Interestingly, in the South, the informality level seems to stabilize for establishments with 25 or more workers (see Table 4 for details). Plausibly, high concentration of informality in small firms has to do with the fact that they are less monitored; on the other hand, as Perry et al. (2007) argue, formality can be seen as an input in the production process for which small firms have little need. On the other hand, it is worth noting that informality rates in medium and even large establishments are far from being negligible. Similar findings for Latin America are reported by Perry et al. (2007: Figure 6.1).

The following five economic activities feature highest dependent informality rates: hotels and restaurants (20\%), personal and household services (18\%), construction (14\%), agriculture (13\%), and 
$\operatorname{trade}^{18}(11 \%)$. The first four activities in this list are also found among the top five in each of the four European regions (see Table 4 for details). This is consistent with previous research on undeclared work (Riedmann and Fischer, 2008: p.23; Williams and Renooy, 2008: p. 9-10; Pedersen, 2003: Figure 4.2) which has revealed construction, household and personal services, trade, and hospitality as the most popular activities among informal workers, as well as the ones with the highest proportions of all workers involved in undeclared work. Yet the same studies suggest that countries and European regions might substantially differ from each other in terms of sectoral distribution of undeclared work. For instance, Williams and Renooy (2008) report that construction activities account for only 3\% of undeclared work in Southern Europe, whilst in the Nordic countries this proportion is 27\%.

However, ESS-based results, reported in Table 6 by categories similar to the ones used in Williams and Renooy (2008), suggest a much smaller geographical variation in sectoral distribution of informal work; in particular, the share of construction is about $10 \%$ in the South and $13 \%$ in the North. ${ }^{19}$ On the other hand, within European regions we find substantial differences between undeclared employees and informal self-employed. In particular, the former are much more concentrated in education and health-related services, as well as in industry, whilst the latter - in agriculture, and (in Eastern and Southern Europe) also in trade, auto repair, and hospitality sector.

\subsection{The dynamics of informal employment}

We conclude this section with a brief overview of the dynamics of informal employment. Table 5 presents changes (in \% points) in estimated prevalence of informal employment and unemployment in the extended labor force of European countries between ESS rounds: round 4 (2008-2009), round 3 (2006-2007), and round 2 (2004-2005). In most cases the changes in both dependent and own-account informal employment are statistically insignificant and small. Between rounds 2 and 3, there have been significant increases in the share of employees without contracts in Portugal (3.6 points), Denmark (2.7 points), Estonia (2.0 points), and Spain (1.0 points). In Portugal and Estonia this has been accompanied by a comparable decrease in the share of informal self-employment, whilst the latter went up as well in Denmark and Spain. A significant decrease in total informal employment between rounds 2 and 3 is found only in the UK (3.3 points) and Slovenia (2.6 points).

The changes between rounds 3 and 4 are of course of special interest because in all countries most of the round 4 field work was during the early stage of crisis (2008/q4 or 2009). From a theoretical perspective, the effect of the recession on informal dependent employment is ambiguous. On the supply side, the workers are likely to be more willing to accept informal employment. On the

\footnotetext{
${ }^{18}$ Including repair of motor vehicles.

${ }^{19}$ The differences in findings between ESS and Eurobarometer survey is likely to be driven by various factors. ESS does not cover secondary jobs; moreover, employed respondents are not asked about their past activities, while the Eurobarometer questions refer to the last 12 months. The seasonal factor might play a role, too: most of the ESS field work has been conducted during autumn and winter months, while it was in the summer for the Eurobarometer. On the other hand, ESS samples are much larger, and, as mentioned above, the quality of ESS field work in the Southern Europe, as well as in Ireland and UK seems to be better.
} 
demand side, there is likely to be much less work left out for outsiders, as private sector employees across Europe have seen substantial working time reductions, and both the firms and the households do not have money for irregular (not urgent) tasks. While firms do have strong incentives to reduce costs via tax avoidance, they might prefer paying envelope wages to workers already on the payroll to using unregistered workers. Yet there is an incentive to conduct as much repair and construction as possible while informal labor is cheap, and this is likely to have a positive effect on informal selfemployment. For a more detailed discussion of relationship between informality and economic cycle we refer to Perry et al. (2007), Bosch and Maloney (2010) and Nikolovova et al. (2010), who have analyzed workers' transitions between formal and informal jobs, and Bajada and Schneider (2009), Schneider et al. (2010) and Hazans (2011c) who have studied the effect of economic growth (among other macro factors) on the size of informal economy and prevalence of informal employment.

Inspection of Table 5 reveals that in countries where a significant change in informal dependent employment has occurred between 2006-2007 and 2008-2009, this change was negative: 6.9 points in Ireland, 5.4 points in Cyprus, 3.9 points in Denmark, 2.4 points in Bulgaria and Latvia, 1.7 points in Netherlands; the only exception was Slovenia with a significant increase by 2.7 points. On the other hand, informal self-employment increased significantly in Poland, Estonia, and Netherlands, whilst in Portugal, Ukraine, Slovenia, Czech R., Slovakia, the UK, and France a (statistically insignificant) increase by 1 to 2 percentage points has been registered; a substantial (by 2 points) decline in the prevalence of informal self-employment is found only in Norway and Switzerland.

Figure 3 which refers to 2004-2009 (and thus covers both growth and recession episodes) suggests a negative association between the change in dependent informality rate and the change in the rate of joblessness within extended labor force. First, the whole scatter diagram is consistent with a downward sloping curve (summarizing both within-countries and between-countries variation in the two indicators). Second, almost all segments connecting the points corresponding to the same country are downward sloping, suggesting that within countries unemployment and informality tend to move in opposite directions (the UK, Hungary, and the Netherlands seem to violate this pattern). Finally, 47 out of 48 observations lie outside the positive quadrant - in other words, there are virtually no cases when the rate of dependent informality and unemployment go up simultaneously. This does not necessarily contradict to the 'safety net story' of displaced workers switching to self-employment (Harris and Todaro, 1970). 


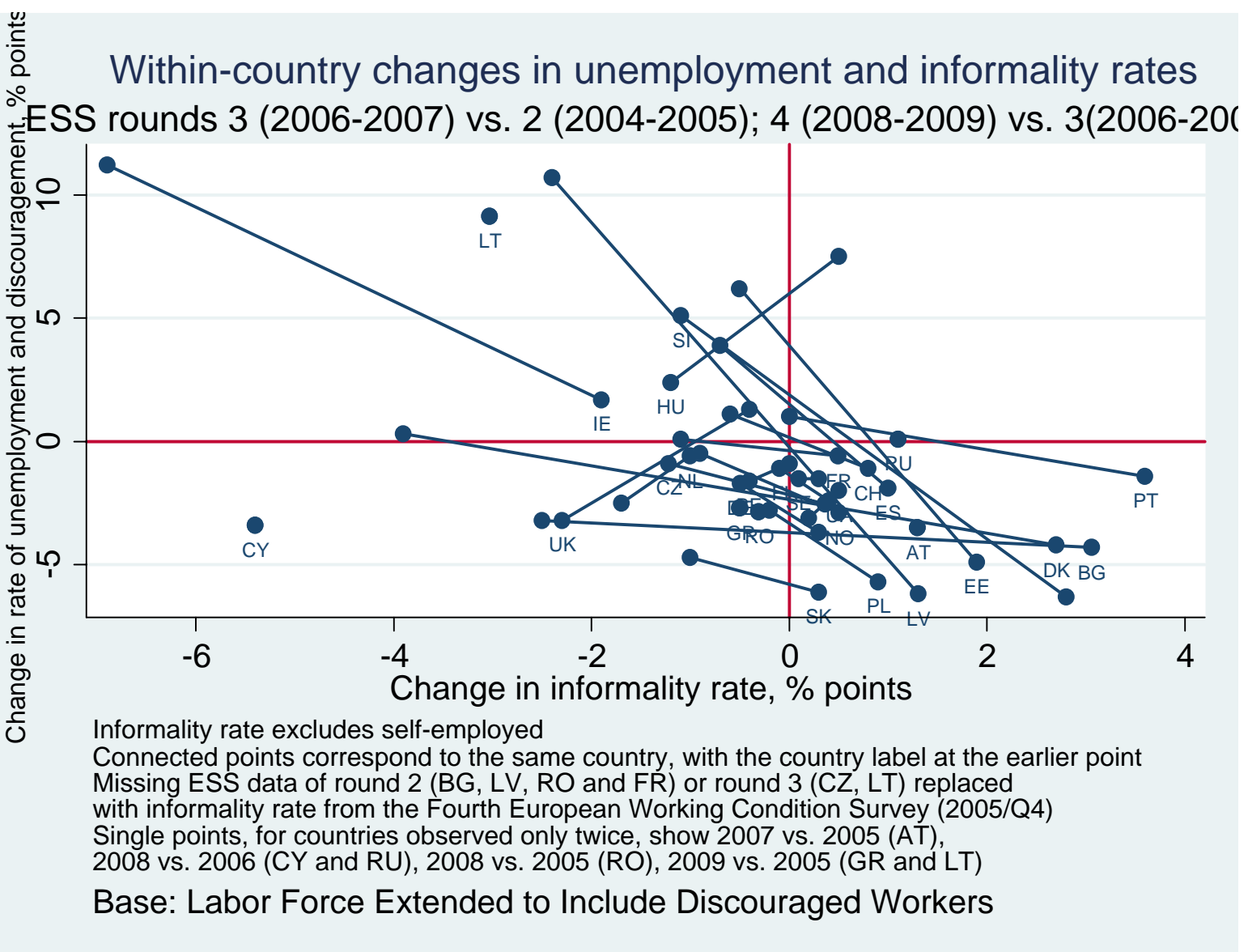

Figure 3 Change in unemployment and discouragement vs. change in informality rate Source: Calculation with ESS, EWCS and EU LFS data

\section{Exclusion factors}

In this section we compare informal and formal workers in terms of factors which could potentially exclude a worker from the formal sector: long-term unemployment experience and perceived discrimination ${ }^{20}$, thus contributing to the "exit vs. exclusion” literature about prevailing reasons for working informally (see Maloney, 1999; Maloney, 2004; Djankov et al., 2003; Hanousek and Palda, 2003; Perry et al. 2007, Williams and Renooy, 2008; Loayza, Servén and Sugawara, 2009; Pfau-Effinger, 2009; Williams, 2009; Schneider, Buehn and Montenegro, 2010). Although heterogeneous nature of self-employment is now well understood in principle, the empirical base in European context remains scarce.

Long-term unemployment experience. Prevalence of long-term unemployment experience among informal employees is much higher than among their formal counterparts (or among informal selfemployed) in most countries (see Figure 4; exceptions include Hungary, Slovakia, Czech R., Norway, Greece, and Cyprus). In 14 countries one tenth to one fifth of shadow employees have been unemployed for more than 12 months during their life, while in Latvia, Belgium, Bulgaria, Netherlands, UK, Portugal, and Italy this proportion ranges from one quarter to one third. This suggest

\footnotetext{
${ }^{20}$ Key characteristics of informal and formal workers are compared in Hazans (2011a: Section 3.1).
} 
that substantial part of the informal wage earners have been forced into informal sector by being rejected in the formal sector.

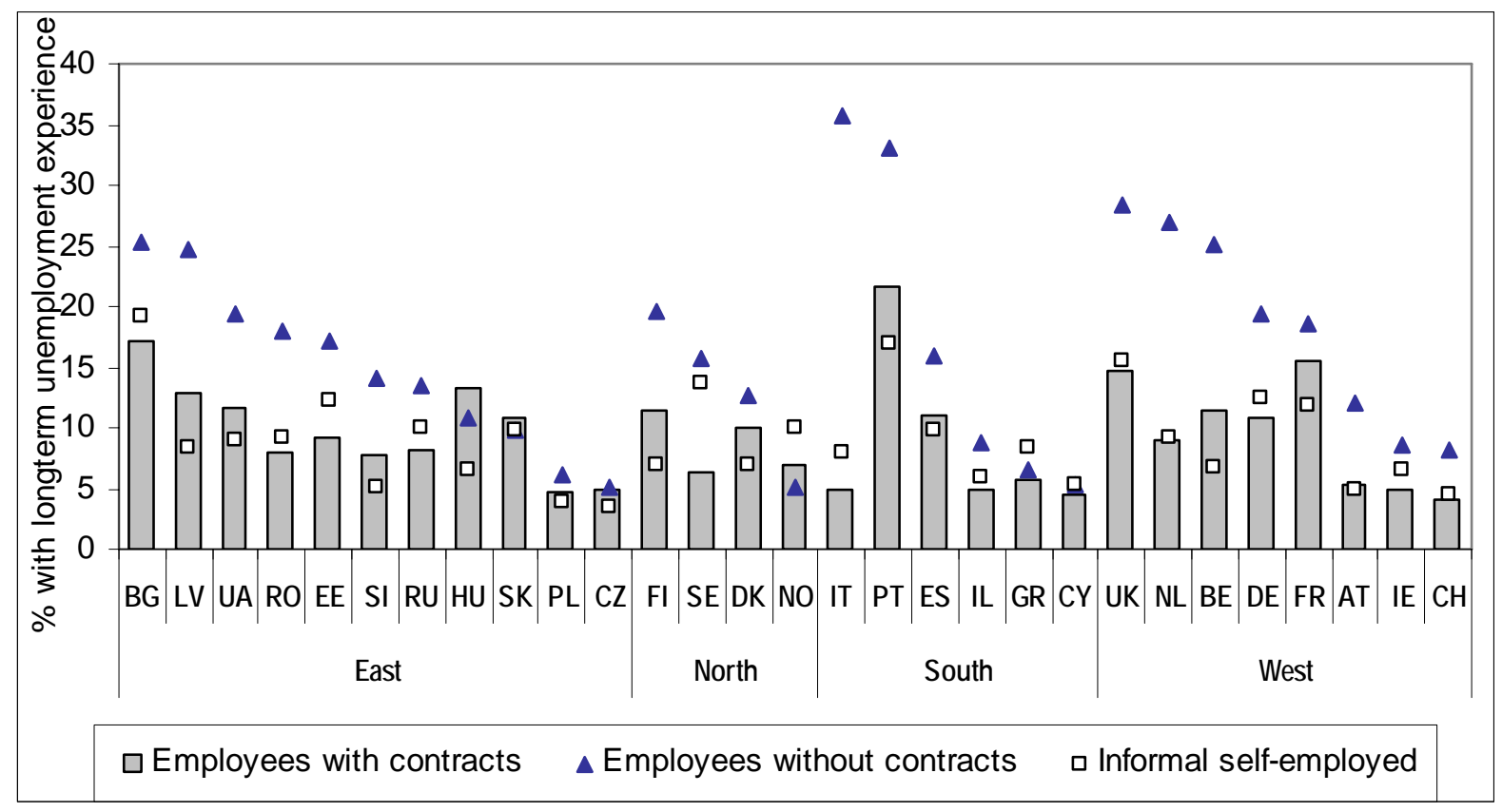

Figure 4 Long-term unemployment experience of formal and informal workers, by country. 2004-2009

Note: The sample size of employees without contracts is less than 30 for IT, SE and FI; between 50 and 90 for CZ, RO, SK, HU, EE, BE, FR, DE and CH; between 100 and 745 for other countries.

Source: Calculation with ESS data.

Perceived discrimination. Figure 5 shows the percentage of formally employed workers, informally employed and informally self-employed who report belonging to a group that suffers from discrimination. The ESS question is phrased "Would you describe yourself as being a member of a group that is discriminated against in this country?”, and specifies discrimination on the grounds of race, nationality, religion, language, ethnicity, age, gender, sexuality and disability. Responses indicate that in most countries a significantly higher share of informal employees consider themselves to be part of a group that faces discrimination than is observed among formal employees and (with exception of Russia) informal self-employed. These differences appear especially large in Spain, Greece and Finland. These findings support the hypothesis that exclusion or poverty escape motive plays an important role in the way how employees end up working without a contract.

Table 7 provides evidence that within European regions the differences in perceived discrimination between informal and formal employees are statistically significant (at the country level the relevant sub-samples are too small). 


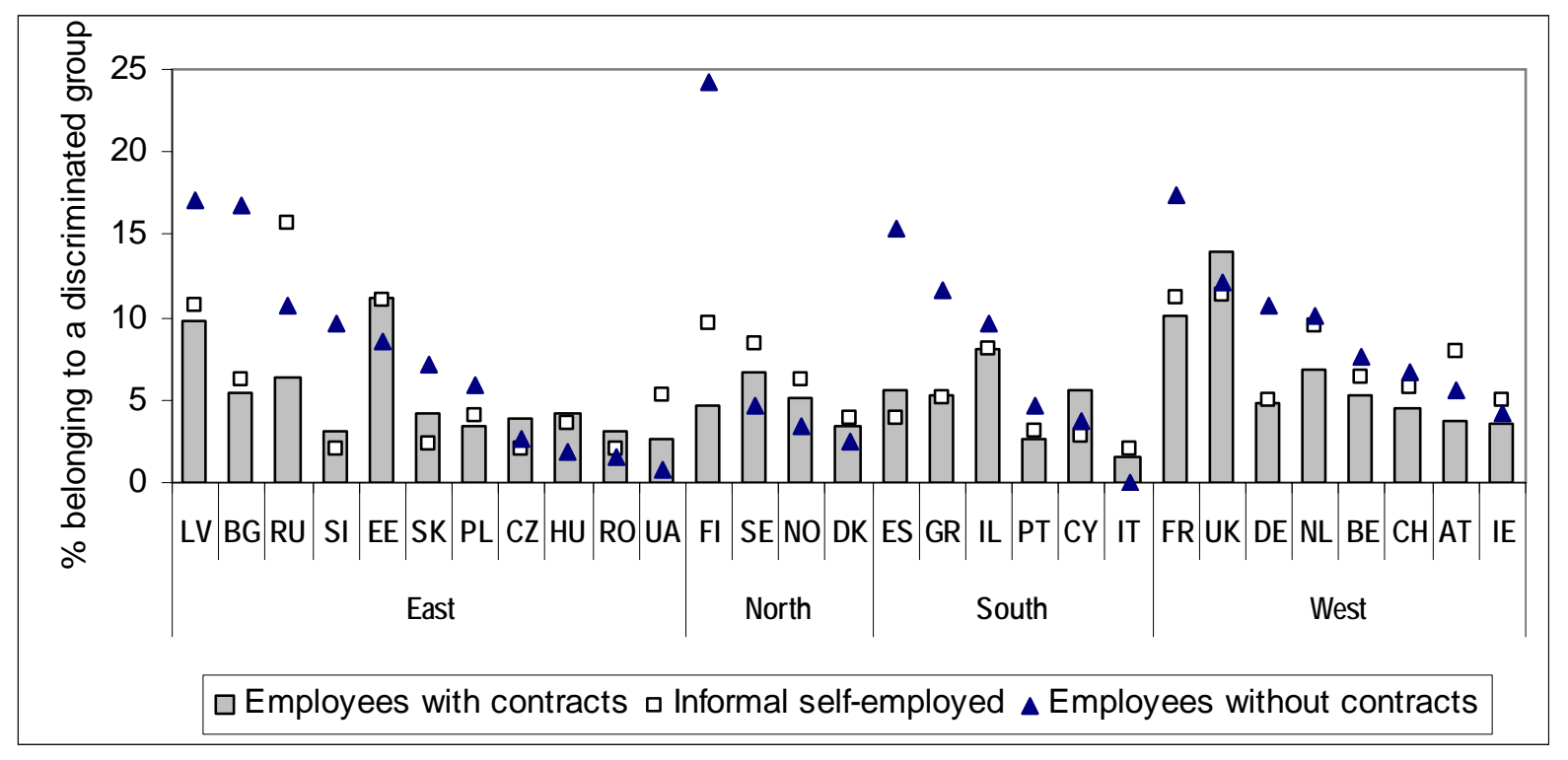

Figure 5 Perceived discrimination among formal and informal workers, by country. 2004-2009

Note: See Note to Figure 4. Source: Calculation with ESS data

\section{Are informal workers poorer than the formal ones?}

Figure 6 (top panel) compares perception of household financial situation by formal and informal employees. In both the Eastern and Southern Europe, the proportion of those seeing their situation as 'very difficult' is much higher among non-contracted workers: $19 \%$ vs. $10 \%$ in the East and $11 \%$ vs. $4 \%$ in the South ${ }^{21}$. The situation is similar when respondents describing their situation as 'difficult' or 'very difficult' are taken together: This category accounts for $53 \%$ of informal employees and just $41 \%$ of formal employees in the East, whilst corresponding figures for the South are $39 \%$ vs. $24 \%$. By contrast, in Western Europe and especially in the Nordic countries, distributions of formal and informal employees among four household income perception categories are rather similar.

The data mentioned above refer to the period between 2004 and 2009. For 2008-2009, round 4 of ESS provides also information on household income decile group within the (unlike the question on income perception) was quite substantial. Figure 6 (bottom panel) summarizes this information (in quintile rather than decile form) by European region, separately for contracted and non-contracted employees. In Eastern and Western Europe, 11\% and 13\%, respectively, of non-contracted employees and just $6.5 \%$ of contracted employees live in the bottom quintile households. In Southern Europe these proportions are $9.9 \%$ vs. $5.4 \%$, whilst in Northern Europe $-8.6 \%$ vs. $2.5 \%$. In other words, while informal workers disproportionally suffer from absolute poverty only in the East and in the South, the incidence of relative poverty among informal workers in much larger than among their formal counterparts in all parts of Europe.

\footnotetext{
${ }^{21}$ These (rounded) figures are obtained after excluding non-response which for the question at hand was quite small. Recall that countries are not weighted by population size.
} 


\section{Household Income Perception by type of Employment \\ In European Regions, 2004-2009}
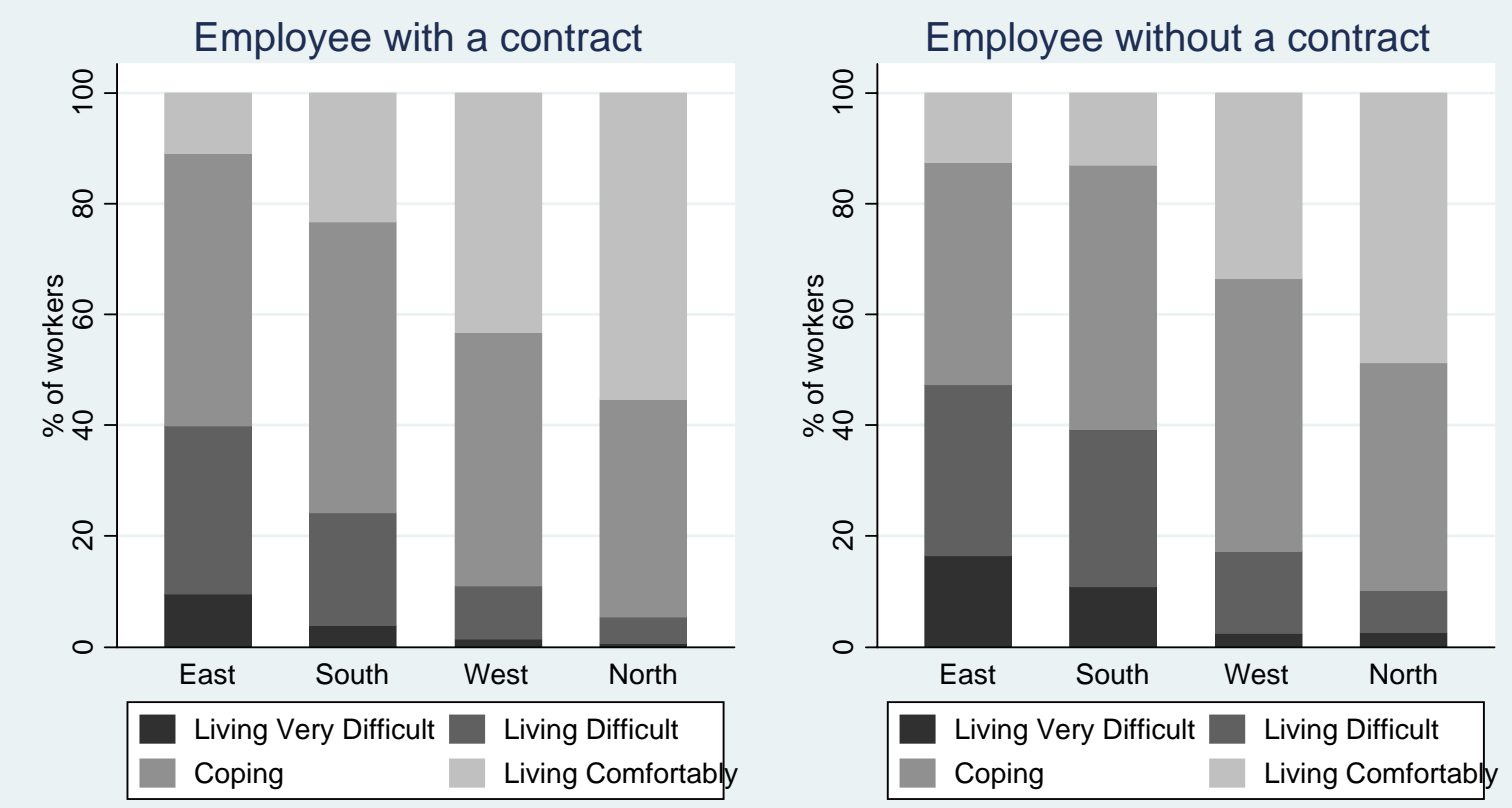

Regions sorted descending by share of low-income households among workers without a contract

Data not weighted by countries' population: A worker from any country is equally likely to be sampled

\section{Household Income Quintiles by type of Employment In European Regions, 2008-2009}
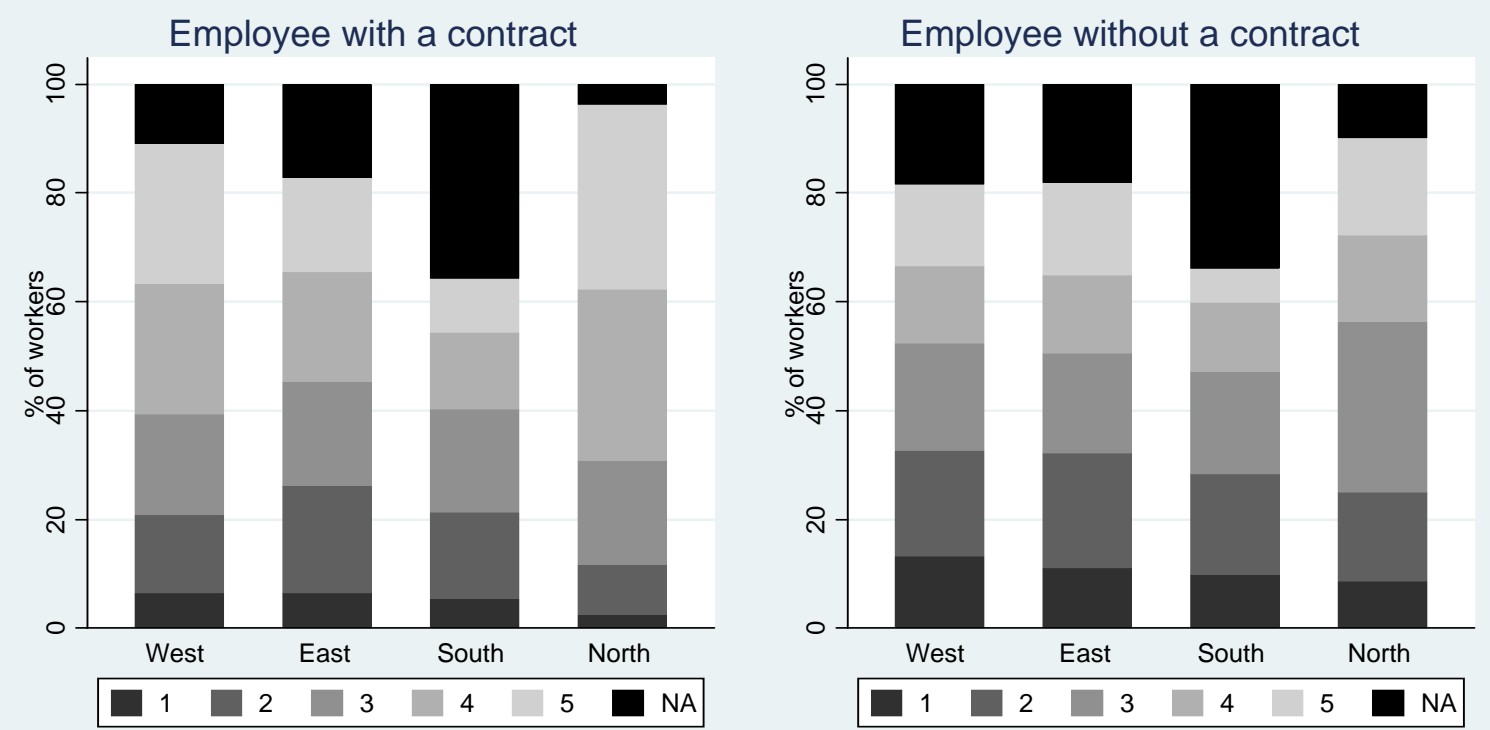

Regions sorted descending by share of low-income households among workers without a contract

Data not weighted by countries' population: A worker from any country is equally likely to be sampled

Figure 6 Perception of household financial situation (Top panel) and household income quintiles (Bottom panel) among formal and informal employees in European regions

Source: Calculation with ESS data.country, although non-response to corresponding question

The results of descriptive analysis are reinforced by ordered probit results (Table 8 and Figure 7), which suggest that after controlling for a rich set of individual characteristics (including parental background, as well as minority/migrant background), informal employees are having the largest 
financial difficulties among all categories of employed population (yet they fare much better than the unemployed and discouraged).

The situation of informal self-employed varies by country group: in the UK, Ireland, Austria and Netherlands, they are as well off as formal employees; in France, Belgium, Germany, and Switzerland, as well as in the Nordic countries and in Southern Europe, they are better off than otherwise similar formal employees, but not by much; and in Eastern Europe they are substantially better off ${ }^{22}$.

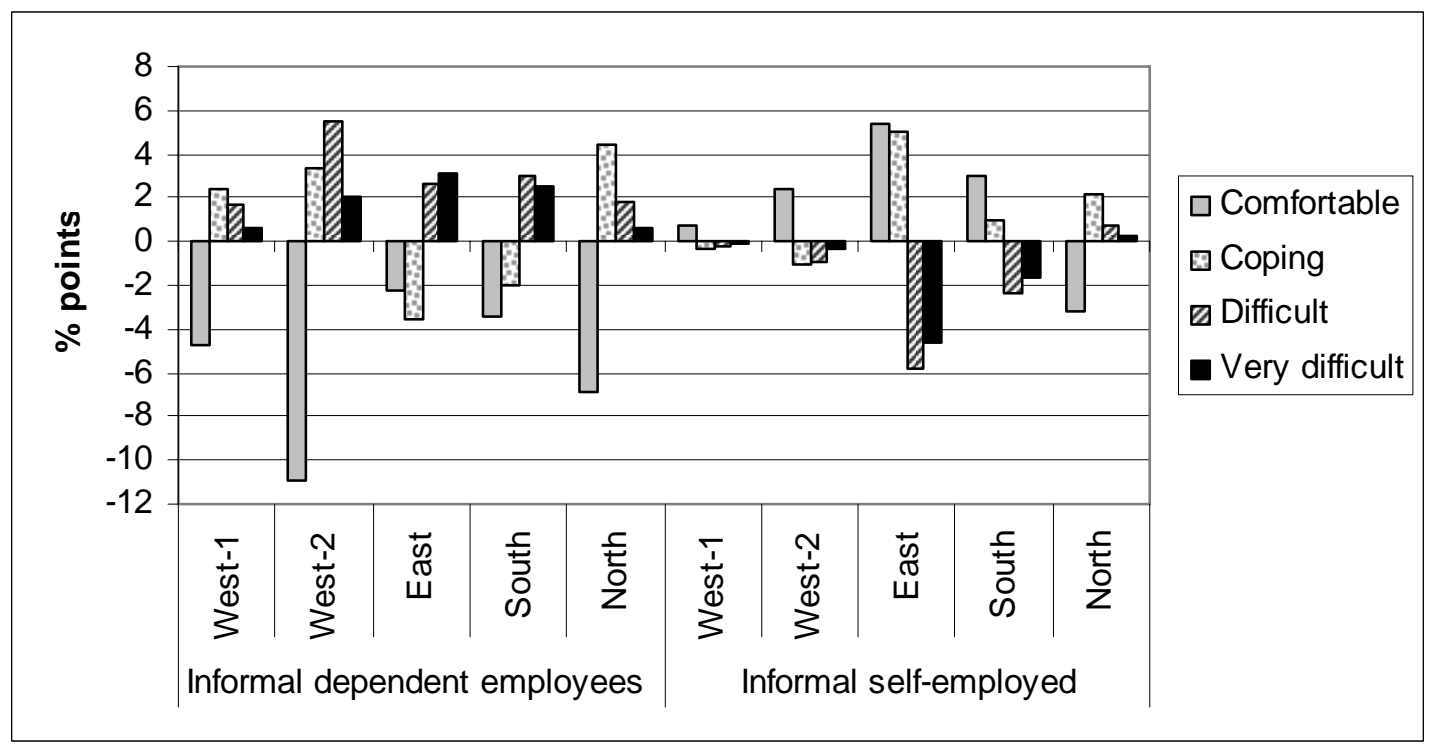

Figure 7 Impact of employment status on perceived household financial situation (ordered probit marginal effects vs. formal employees)

Source: Calculation with ESS data (based on model reported in Table 8).

Note that these results are not subject to selection bias because non-response to the question on self-assessment of household's financial situation is quite small, and non-employed population is included in the sample. Yet we cannot claim that the relationship is causal because the same unobserved factors can influence propensity to work informally and propensity to experience financial hardship, although presence of parental background controls mitigates this problem.

Our findings are qualitatively similar to those by Perry et al. (2007: Chapter 3) on Latin America: in Argentina, informal salaried workers have substantially higher income-poverty and self-rated poverty rates than formal salaried workers; in Dominican Republic, the same is true for incomepoverty and dissatisfaction with employee benefits (but not for self-rated poverty and dissatisfaction with earnings); and in Colombia, for dissatisfaction with both earnings and employee benefits. Moreover, earnings of informal employees are, on average, by more than $40 \%$ lower than those of formal workers in Bolivia and Dominican Republic and by more than 60\% in Argentina. These earnings and welfare gaps remain significant after controlling for worker characteristics in some cases

\footnotetext{
${ }^{22}$ In this analysis, we do not account for coordinated labor supply decisions within household. This awaits a separate study (there are, however, some data limitations).
} 
but become insignificant in others. In most cases, welfare and/or earnings disadvantage of informal self-employed is either smaller or absent (or disappears after controlling for characteristics).

\section{Determinants of work without a contract}

In this section, to test empirically the predictions of the model outlined in Section 1, we present the results of econometric analysis of individual determinants of work without a contract among employees, ignoring the effects of selection into dependent employment. Thus, we are modeling the "choice" between formal and informal dependent employment, once the worker has, for the given period, chosen paid work over self-employment or non-employment. Note that the potential selection bias is mitigated by presence of parental background controls which proxy for unobserved ability.

The results are presented in Table 9 separately for seven country groups which appear to be homogenous with respect to the main effects ${ }^{23}$ :

(i) East-1: Poland, the Czech R, Slovakia, Estonia, Latvia, Lithuania, Russia, Ukraine, and Bulgaria;

(ii) East-2: Hungary, Romania and Slovenia;

(iii) North: Sweden, Norway, Finland and Denmark;

(iv) West-1: the Western European countries with high informality level (Ireland, UK, Austria), joined by the Netherlands, where the direction of the main effects appears to be largely similar to the ones found in the other three countries, and the legal requirements on employee contracts are similar to those in the UK and Ireland (see Table A1 in the Annex);

(v) West-2: Germany, Switzerland, France, and Belgium, which feature broadly similar level and structure of informal employment (let aside being German and/or French-speaking);

(vi) South-1: Spain, Portugal and Israel;

(vii) South-2: Italy, Greece and Cyprus.

The models are mixed-effects logits (see Train, 2003; Greene, 2008: pp. 851-852) with country and year fixed effects (capturing the macro factors) and region-level random effects, capturing regionspecific differences in economic development and/or in social norms. Here "regions" are NUTS level 1 for Germany, France, the UK and Spain; NUTS level 3 for the Baltic countries, the Netherlands, Bulgaria and Slovenia; and NUTS level 2 for remaining countries, except for Russia (10 federal regions) and Ukraine (26 “oblast's” surrounding largest cities).

Except for Nordic countries, Hungary, Romania and Slovenia, we have found a substantial within-country regional variation in informality: estimated standard deviations of the random effects are significant at $1 \%$ level in East-1, West-1, South-1 and South-2, and significant at $5 \%$ level in

\footnotetext{
${ }^{23}$ Single-country models have been estimated and compared as a preliminary stage of analysis.
} 
West-2; the [conservative] LR tests comparing estimated models with the ones without random effects are also highly significant in East-1, West-1, South-1 and South-2, and significant at $11 \%$ level in West-2.

For East-2 and North, where informality differences across regions are not large enough, we present models where region-level random effects are integrated over the sample, i.e. populationaveraged models estimated by the Generalized Estimating Equations (GEE) method (see Liang and Zeger 1986) ${ }^{24}$.

The results are consistent with the predictions of the model outlined in Section 1, as well as with the descriptive statistics discussed in Sections 2 and 3. In all country groups, the propensity to work without a contract is inversely related to education level, although the patterns and the strength of this effect varies by country group. Students are much more likely to work informally than otherwise similar other workers. In four out of seven country groups, the same holds also for workers with a disability or a chronic illness. Even after controlling for being a student, the age-informality profile is U-shaped, with the minimum ranging between 37 and 48 years, depending on country group. The only exception is the South-1 group (Spain, Portugal, and Israel), where the minimum is at 21 years of age among non-students (and at 27 years if being a student is not controlled for). Recall that both the young and the elderly, as well as persons with permanent health problems, apart from lower-thanaverage productivity, are likely to have a source of non-labor income, to be less concerned with the job security, to have rather volatile preferred number of hours worked, and to place a high value on flexible work schedule. Moreover, the students, the pensioners and the disabled, by the group belonging, are likely to have large informal social capital and are more likely than others to receive informal job offers.

After accounting for the sector of employment, the gender effect varies by country group (plausibly, reflecting the differences in informality traditions across countries). In Eastern Europe (except Romania and Slovenia), female workers are less likely to be informal than otherwise similar male workers; in Nordic countries this is true only for non-single females. In Belgium and France, we have not found a significant gender effect, whilst in the rest of Western Europe, as well as in Southern Europe female workers are more likely to work without a contract than their male counterparts (in Greece, Cyprus and Italy this applies only to childless females).

In Eastern Europe, as well as in Israel, workers with either ethnic minority or immigrant background have a significantly higher propensity to work without a contract than otherwise similar native workers ${ }^{25}$. In Eastern Europe, this effect is less pronounced for those with only one parent being immigrant, as well as for immigrants from EU countries. In Spain and Portugal, all immigrants, both from EU and non-EU countries, face a substantially higher risk of informality than native workers (the

\footnotetext{
${ }^{24}$ For the other five country groups, the marginal effects from population-averaged logit estimates are similar to the ones presented in Table 9.

${ }^{25}$ This result does not apply to Hungary, Romania, and Slovenia. However, at least for the former two countries, this might be due to data limitations: It is well documented (see e.g. Kahanec et al., 2010; Kahanec and Zimmermann, 2011), that informal employment is common among Roma population across Eastern Europe. Yet this minority group is severely under-represented in ESS samples for Hungary and Romania.
} 
marginal effect is 13 to 15 percentage points); however, this is not the case for second generation immigrants. In Italy, Greece, and Cyprus we found a significantly higher informality risk only for immigrants not covered by the free movement of labor provisions (the marginal effect is 21 percentage point), as well as for „mixed” second generation immigrants (13 percentage points). With regards to Italy this result should be interpreted carefully because the Italian data cover only year 2006, and the sub-sample of informal employees is pretty small.

In the UK, Ireland, Austria, and the Netherlands, immigrants not covered by the free movement of labor provisions constitute the only group among population with immigrant or minority background featuring a significant informality effect (5.6 percentage points above native workers). It is worth noting that belonging to this group is clearly an exogenous variable - unlike having an individual work permit.

Remarkably, in Nordic countries, as well as in Germany, Switzerland, France and Belgium, none of the minority or immigrant groups, after controlling for other observable characteristics, features a higher informality rate than the native employees. See, however, Hazans (2011b; 2011c) for a simultaneous analysis of informal dependent employment, informal self-employment, unemployment and inactivity.

In Eastern Europe (but not elsewhere), workers who are return migrants are more likely to be employed informally. This is consistent with the idea that a substantial part (although not necessarily a majority) of return migrants might be "negatively selected” out of home-country's labor force, and their return is an evidence of not being successful abroad as well. It is enough if the proportion of such low-productivity workers among return migrants would be substantially higher than the informality rate among stayers, which is about $5 \%$ in the Eastern Europe, and such a situation is quite a likely outcome; Hazans (2008) shows that about 25\% of return migrants are negatively selected.

It is worth mentioning that some of the results obtained are similar to those by Jonasson (2011) who studied determinants of informality in urban labor markets of Brazil using a probit model. This concerns the negative education effect, the U-shaped age-informality profile, and the positive effects of being an immigrant (Jonasson controls for a rural-urban immigrant) or disabled.

The results presented in this section change very little when the models control also for individual satisfaction with the government (measured in 0-10 scale), see Hazans (2011a).

\section{Conclusion}

In this paper we have compared the prevalence of informal employment in 30 European countries using data from the European Social Survey. Overall size of informal employment decreases from the South to West to East to North, but the median prevalence of dependent informal employment is higher in the East than in the West. Yet there is a strong heterogeneity within these geographical areas. In particular, Western Europe is split into highly informal part (Ireland, the UK, and Austria) on one hand and the continental part (without Austria), where work without contract is quite rare, although informal self-employment is more prevalent than in most of Eastern Europe. We 
have found a substantial within-country regional variation in informality in all countries except for Nordic countries, Hungary, Romania and Slovenia.

In all parts of Europe, the dependent informality rate is inversely related to skills (measured in terms of either schooling or occupation). The low-educated, the young (especially students), the elderly, and persons with permanent health problems are more likely to work informally, other things equal.

Both in Southern and in Western Europe, the highest dependent informality rate is found among immigrants from CEE and former Soviet Union, whilst in Eastern Europe this group is second after local born minorities without immigrant background. In Southern Europe (especially in Spain, Portugal, and Greece) immigrants not covered by the "free movement of labor" provisions are more likely to work without contract than both natives and covered immigrants. Both in Eastern and Southern Europe, as well as in highly informal part of Western Europe, these not covered immigrants have significantly higher propensity to work without contracts also after controlling for individual characteristics.

Our findings lend support to theoretical arguments that apart from low productivity, informality drivers include "informal" social capital, low value placed on job security, and preference for flexible working time and/or substantial volatility of desired working hours.

We provide evidence that exclusion and discrimination play important role in pushing employees into informality, whilst this seems not to be the case for informal self-employed. Both on average and after controlling for a rich set of individual characteristics, informal employees in all parts of Europe are having the largest financial difficulties among all categories of employed population (yet they fare much better than the unemployed and discouraged), whilst informal self-employed are at least as well off as formal employees.

\section{References}

Ambrosini, M. (2001). The role of immigrants in the Italian labour market. International Migration, 39 (3): 61-83.

Basu, A.K., N. H. Chau and R. Kahbur (2011). Contractual dualism, market power and informality. IZA Discussion Paper No. 5845.

Bernabè, S. (2008). Measuring Informal Employment in Transition Countries. University of Leuven, mimeo

Boeri, T. and P. Garibaldi (2005). Shadow Sorting, in C. Pissarides and J. Frenkel (eds), NBER Macroeconomics Annual, MIT Press, Cambridge, MA, 2005.

Boeri, T., P. Garibaldi and M. Ribeiro (2011). The lighthouse effect and beyond. Review of Income and Wealth, 57: S54-S78.

Bosch, M., E. Goni and W. Maloney (2007). The Determinants of Rising Informality in Brazil: Evidence from Gross Worker Flows. World Bank Policy Research Working Paper No. 4375. 
Bosch, M., and W. Maloney (2010). Comparative Analysis of Labor Market Dynamics Using Markov Processes: An Application to Informality. Labour Economics 17(4): 621-631.

De Paula, Á. and J. A. Scheinkman (2011). The informal sector: An equilibrium model and some empirical evidence from Brazil. Review of Income and Wealth, 57: S8-S26.

Djankov S., I. Lieberman, J. Mukherjee and T. Nenova (2003). Going Informal: Benefits and Costs. In B. Belev (ed.) “The Informal Economy in the EU Accession Countries: Size, Scope, Trends and Challenges to the Process of EU Enlargement”. Sofia: CSD: 63-80.

EURES - the European Job Mobility Portal (2011). Living \& Working. http://ec.europa.eu/eures/main.jsp?acro=lw\&lang=en\&catId=490\&parentId=0

European Foundation for the Improvement of Living and Working Conditions (2007). European Working Conditions Survey, 2005 [computer file]. Colchester, Essex: UK Data Archive [distributor], May 2007. SN: 5639

European Social Survey (2004-2009). Data files: Round 2 (edition 3.2), Round 3 (edition 3.3), Round 4 (edition 4.0). Norwegian Social Science Data Services.

Feld, L. P. and F. Schneider (2010). Survey on the Shadow Economy and Undeclared Earnings in OECD Countries. German Economic Review 11(2): 109-149

Fialova, K. and O. Schneider (2011). Labor Institutions and their Impact on Shadow Economies in Europe. Background paper for "In from the Shadow: Integrating Europe's Informal Labor" World Bank, Washington DC, mimeo

Flaquer, L. and A. Escobedo (2009). The metamorphosis of informal work in Spain: family solidarity, female immigration and development of social rights'. In B. Pfau-Effinger, L. Flaquer and P. H. Jensen (eds.), Formal and Informal Work in Europe. The Hidden Work Regime. London, New York: Routledge, pp. 143-62.

Frey, B. S. and H. Weck-Hanneman (1984). The Hidden Economy as an "Unobserved" Variable. European Economic Review 26(1): 33-53.

Greene, W. H. (2008). Econometric Analysis. 6th ed. Upper Saddle River, NJ: Prentice-Hall. Hanousek, J. and F. Palda (2003). Why People Evade Taxes in the Czech and Slovak Republics:

A Tale of Twins. In B. Belev (ed.) The Informal Economy in the EU Accession Countries: Size, Scope, Trends and Challenges to the Process of EU Enlargement. Sofia: CSD: 139-174.

Harris, J. and M. Todaro (1970). Migration, Unemployment, and Development: A TwoSector Analysis. American Economic Review, 60(1):126-42.

Hazans, M. (2008). Post-enlargement return migrants' earnings premium: Evidence from Latvia. EALE 2008 paper No. 541, 2008. Available at SSRN: http://ssrn.com/abstract=1269728

Hazans, M. (2011a). Informal workers across Europe: Evidence from 30 European countries. Background paper for "In from the Shadow: Integrating Europe's Informal Labor". World Bank: Washington DC, mimeo: http://www.iza.org/conference_files/InfoETE2011/hazans_m1142.pdf Hazans, M. (2011b). Determinants of Employment Status and (In)Formality: A nested logit approach (forthcoming in IZA Discussion Papers). 
Hazans, M. (2011c). What Explains Prevalence of Informal Employment in European Countries: The Role of Labor Institutions, Governance, Immigrants, and Growth.

IZA Discussion Paper No. 5872.

Heckman, J., and G. Sedlacek (1985). Heterogeneity, aggregation, and market wage functions: An empirical model of self-selection in the labor market. Journal of Political Economy 93 (6): $1077-1125$.

Henley A., G. R. Arabsheibani and F. G. Carneiro (2006). On Defining and Measuring the Informal Sector. World Bank Policy Research Working Paper 3866

Hussmanns, R. (2004). Measuring the Informal Economy: From Employment in the Informal Sector to Informal Employment, ILO Bureau of Statistics Working Paper No. 53.

ILO (2002). Women and Men in the Informal Economy: A Statistical Picture. Geneva: ILO.

ILO (2003): Guidelines concerning a statistical definition of informal employment, in: Seventeenth International Conference of Labour Statisticians, Report of the Conference; Doc. ICLS/17/2003/R. Geneva: ILO

Jonasson, E. (2011). Government Effectiveness and Regional Variation in Informal Employment. http://www.iza.org/conference_files/InfoETE2011/jonasson_e6968.pdf (forthcoming in Journal of Development Studies).

Kahanec, M. and A. Zaiceva (2009). Labor market outcomes of immigrants and non-citizens in the EU: An East-West comparison. International Journal of Manpower, 30 (1/2), 97-115.

Kahanec, M., A. Zaiceva and K. F. Zimmermann (2010). Ethnic Minorities in the European Union: An Overview. IZA Discussion Paper No. 5397.

Kahanec, M. and K. F. Zimmermann (eds) (2011). Ethnic diversity in European labor markets: Challenges and solutions, Cheltenham: Edward Elgar Publishing (forthcoming).

Liang, K.-Y. and S. L. Zeger (1986). Longitudinal data analysis using generalized linear models. Biometrika 73 (1): 13-22.

Loayza, N.V., L. Servén and N. Sugawara (2009). Informality in Latin America and the Caribbean. World Bank Policy Research Working Paper No. 4888.

Maloney, W. (1999). Does Informality Imply Segmentation in Urban Labor Markets? Evidence from Sectoral Transitions in Mexico. The World Bank Economic Review, 13 (2): 275 - 302.

Maloney, W. F. (2004). Informality revisited. World Development, 32 (7): 1159-1178.

Muravyev, A. (2010). Evolution of Employment Protection Legislation in the USSR, CIS and Baltic States, 1985-2009, IZA Discussion Paper No. 5365.

Nikolovova, P., F. Pertold and M. Vozar (2010). Informal Economy in the Czech and Slovak Republics: Microeconometric Analysis of Labor Force Transitions. Background paper for "In from the Shadow: Integrating Europe's Informal Labor". World Bank, Washington DC, mimeo.

Novinite (2011). 1/5 of Bulgarian Employees Work in Gray Economy. http://www.novinite.com/view_news.php?id=125106 
OECD (2009). Is Informal Normal? Towards More and Better Jobs. Paris: OECD.

Packard, T. G. (2000) "Do Workers in Chile Choose Informal Employment? A Dynamic Analysis of Sector Choice”. Washington D.C.: The World Bank (mimeo).

Pedersen, S. (2003). The Shadow Economy in Germany, Great Britain and Scandinavia:

A Measurement Based on Questionnaire Surveys. Copenhagen: The Rockwool Foundation Research Unit, Study no. 10.

Perry, G., W. Maloney, O. Arias, P. Fajnzylber, A. Mason and J. Saavedra-Chanduvi (2007). Informality: Exit and Exclusion. Washington D.C.: The World Bank

Pfau-Effinger, B. (2009). Varieties of Undeclared Work in European Societies. British Journal of Industrial Relations 47 (1): 79-99

Pissarides, C. (2000). Equilibrium unemployment theory. MIT Press.

Riedmann, A. and G. Fischer (2008). Undeclared work in the European Union. Special Eurobarometer 284: Report.

Schneider, F. (2005). Shadow Economies around the World: What Do We Really Know. European Journal of Political Economy 21, 598-642.

Schneider F., Buehn A., Montenegro C.E. (2010). Shadow Economies All over the World: New Estimates for 162 Countries from 1999 to 2007 (Revised Version). World Bank Policy Research Working Paper No. 5356.

Say, F. (2011), Does employment protection help immigrants? Evidence from European labour markets. Labour Economics (forthcoming, doi:10.1016/j.labeco.2011.01.006 )

Slonimczyk, F. (2011). The Effect of Taxation on Informal Employment: Evidence from the Russian Flat Tax Reform. Moscow: Higher School of Economics, mimeo http://www.iza.org/conference_files/InfoETE2011/slonimczyk_f6969.pdf

Torgler, B. (2007). Tax Compliance and Tax Morale: A Theoretical and Empirical Analysis, Cheltenham, UK: Edward Elgar

Torgler, B. (2010). Tax Morale, Eastern Europe and European Enlargement. Background paper for In from the Shadow: Integrating Europe's Informal Labor, a World Bank regional report on the informal sector in Central, Southern Europe and the Baltic countries (Task number P112988).

Train, K. (2003). Discrete Choice Methods with Simulations, Cambridge: Cambridge University Press. Williams, C. C. (2009). Formal and Informal Employment in Europe: Beyond Dualistic Representations. European Urban and Regional Studies 16(2): 147-159

Williams, C. C. and P. Renooy (2008). Measures to Tackle Undeclared Work in the European Union. Dublin: European Foundation for the Improvement of Living and Working Conditions. 
Table 1 Classification of extended labor force (economically active and marginally attached population) based on European Social Survey data

\begin{tabular}{|c|c|c|}
\hline No. & Category & \multicolumn{1}{c|}{ Definition } \\
\hline 1 & Formal employment & $\begin{array}{c}\text { Formal employment includes the following two groups: } \\
\text { (i) Employees holding an employment contract; } \\
\text { (ii) Persons working for own family's business and having a contract. }\end{array}$ \\
\hline 2 & Formal self-employment & $\begin{array}{c}\text { Formal self-employment includes the following two groups: } \\
\text { (i) Employers with more than 5 workers; } \\
\text { (ii) Self-employed working as professionals (without workers) }\end{array}$ \\
\hline 3 & $\begin{array}{c}\text { Informal self-employment } \\
\text { Informal self-employment includes the following two groups: } \\
\text { (i) All non-professional self-employed operating solely; } \\
\text { (ii) Employers with 5 or fewer workers }\end{array}$ \\
\hline 4 & Family workers & Persons working without a contract for own family's business \\
\hline 6 & $\begin{array}{c}\text { Informal dependent } \\
\text { employment }\end{array}$ & $\begin{array}{c}\text { Employees (persons in a dependent employment relationship) } \\
\text { without a contract or who is uncertain of their contract. }\end{array}$ \\
\hline
\end{tabular}

Notes: This classification is fully applicable to ESS data starting from round 2. In round 1, it was not possible to distinguish between categories 1 and 5. Moreover, due to data limitations, the classification is applicable to French data only starting from round 3, and to Romanian data - from round 4.

Table 2 Prevalence of informal employment in Europe, by region. 2008-2009

Per cent

\begin{tabular}{|c|c|c|c|c|c|c|c|c|c|c|}
\hline & \multicolumn{10}{|c|}{ A. Estimates based on current (during the survey week) status of respondents } \\
\hline & \multirow{2}{*}{\multicolumn{4}{|c|}{$\begin{array}{l}\text { Employees without a contract } \\
\text { as a share of all employees }\end{array}$}} & \multirow{2}{*}{\multicolumn{6}{|c|}{ Total informal employment as a share of }} \\
\hline & & & & & & & & & & \\
\hline & \multirow{2}{*}{\multicolumn{2}{|c|}{$\begin{array}{l}\text { Non-response } \\
\text { about contract } \\
\text { excluded } \\
\text { a }\end{array}$}} & \multirow{2}{*}{\multicolumn{2}{|c|}{$\begin{array}{l}\text { Non-response } \\
\text { treated as } \\
\text { „No contract” } \\
\text { a }\end{array}$}} & \multirow{2}{*}{\multicolumn{2}{|c|}{$\underset{\mathrm{a}}{\text { Total }} \underset{\mathrm{b}}{\text { employment }}$}} & \multicolumn{2}{|c|}{$\begin{array}{l}\text { Extended labor } \\
\text { force }\end{array}$} & \multicolumn{2}{|c|}{$\begin{array}{l}\text { Population } \\
\text { aged } 15+\end{array}$} \\
\hline & & & & & & & & & & \\
\hline South & 9.5 & 20.2 & 10.1 & 21.1 & 28.2 & 35.6 & 24.5 & 31.3 & 14.0 & 18.5 \\
\hline West & 5.1 & 6.3 & 5.5 & 7.1 & 15.8 & 17.8 & 14.5 & 16.4 & 8.9 & 10.1 \\
\hline East & 5.2 & 3.8 & 6.7 & 5.3 & 14.8 & 13.6 & 13.4 & 11.9 & 7.9 & 6.9 \\
\hline orth & 2.7 & 2.6 & 2.7 & 2.7 & 10.7 & 11.1 & 10.3 & 10.6 & 6.6 & 6.7 \\
\hline tal & 5.8 & 8.0 & 6.6 & 8.6 & 17.4 & 19.3 & 15.7 & 17.4 & 9.4 & 10 \\
\hline
\end{tabular}

B. Lower bound estimates of the population engaged in informal employment during the last year ${ }^{c}$

Non-employed population members who were recently informally employed, as a share of current extended labor force

Total population recently engaged in informal employment as a share of

$$
\underset{\mathrm{a}}{\operatorname{Recent} \text { employees }} \quad \text { Total }
$$

$\begin{array}{ccccc}\text { South } & 2.7 & 4.7 & 3.6 & 5.5 \\ \text { West } & 2.0 & 2.8 & 3.0 & 3.8 \\ \text { East } & 3.3 & 2.9 & 4.1 & 4.0 \\ \text { North } & 1.1 & 1.1 & 1.5 & 1.5 \\ \text { Total } & 2.6 & 3.1 & 3.5 & 4.0\end{array}$

\begin{tabular}{cccc}
$\begin{array}{c}\text { Extended labor } \\
\text { force }\end{array}$ & \multicolumn{2}{c}{$\begin{array}{c}\text { Population } \\
\text { aged }\end{array}{ }^{+}{ }^{2}$} \\
a & b & a & b \\
28.1 & 36.7 & 16.1 & 21.7 \\
17.5 & 20.2 & 10.7 & 12.4 \\
17.6 & 15.8 & 10.3 & 9.2 \\
11.8 & 12.1 & 7.6 & 7.7 \\
19.2 & 21.3 & 11.4 & 12.8
\end{tabular}

Notes: Total informal employment includes categories 3-5 (Table 1). See Table 3 for the list of countries in each of the four European region, as well as details on the period of field work. Note that South includes Italy with year 2006 data, whilst West includes Austria with year 2007 data. ${ }^{\text {a }}$ Countries weighted by population.

b Countries weighted equally (i.e. a respondent from any country is equally likely to be sampled). ${ }^{\mathrm{c}}$ Exact reference period varies by country, but on average it is close to 12 months in each of the four European region: 11 months for the North, 11.6 months for the West, 12.6 months for the South, and 14.6 months for the East. 
Table 3 Extended labor force by proximity to formal employment. Selected European countries, 2008-2009

\begin{tabular}{|c|c|c|c|c|c|c|c|c|c|c|c|c|c|}
\hline \multirow[b]{2}{*}{ Country } & \multirow[b]{2}{*}{$\begin{array}{l}\text { Core } \\
\text { Period }\end{array}$} & \multicolumn{3}{|c|}{$\begin{array}{c}\text { Formal } \\
\text { Employment }\end{array}$} & \multicolumn{4}{|c|}{ Informal Employment } & \multicolumn{3}{|c|}{$\begin{array}{l}\text { Unemployed } \\
\text { Willing to Work }\end{array}$} & \multirow{2}{*}{ 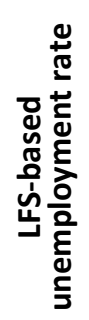 } & \multirow{2}{*}{ 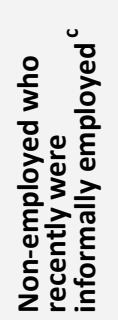 } \\
\hline & & 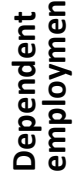 & 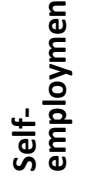 & 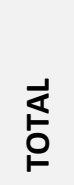 & 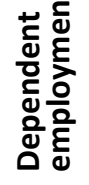 & 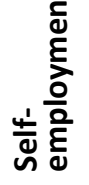 & 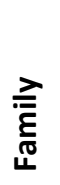 & 衣 & 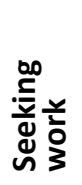 & 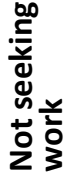 & 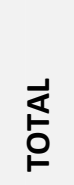 & & \\
\hline \multicolumn{14}{|c|}{ Southern Europe } \\
\hline Cyprus & 2008/q4 & 38.8 & 4.3 & 43.1 & 35.2 & 14.5 & 3.3 & 53.0 & 2.0 & 1.9 & 3.9 & 3.6 & 3.7 \\
\hline Greece & 2009/q3 & 37.0 & 2.3 & 39.3 & 18.2 & 26.2 & 2.3 & 46.7 & 8.0 & 6.0 & 14.0 & 9.5 & 5.7 \\
\hline Israel & 2009/q1 & 46.0 & 4.4 & 50.4 & 25.5 & 10.7 & 0.6 & 36.8 & 8.6 & 4.1 & 12.7 & 6.8 & 12.3 \\
\hline Italy ${ }^{a}$ & 2006/q1 & 59.0 & 3.7 & 62.7 & 2.9 & 19.2 & 0.3 & 22.4 & 9.3 & 5.5 & 14.8 & 7.1 & 4.1 \\
\hline Portugal & 2009/q1 & 62.9 & 1.3 & 64.2 & 7.6 & 13.8 & 1.0 & 22.4 & 10.1 & 3.3 & 3.4 & 8.5 & 2.8 \\
\hline Spain & 2008/q4 & 68.4 & 2.2 & 70.6 & 4.4 & 13.9 & 0.5 & 18.8 & 7. & 2.9 & 10.7 & 13.0 & 1.3 \\
\hline \multicolumn{14}{|c|}{ Eastern Europe } \\
\hline Poland & 2008/q4 & 65.9 & 2.0 & 67.9 & 4.1 & 16.6 & 0.9 & 21.6 & 7.1 & 3.5 & 10.6 & 6.8 & 4.4 \\
\hline Ukraine & 2009/q1 & 73.9 & 0.9 & 74.8 & 6.9 & 7.3 & 0.2 & 14.4 & 8.4 & 2.4 & 0.8 & 9.5 & 5.1 \\
\hline Slovenia & 2008/q4 & 74.4 & 1. & 75.7 & 6.2 & 7.2 & 0 & 14.1 & 4.9 & 5.3 & 0.2 & 4.3 & 5.8 \\
\hline Bulgaria & 09/q1 & 65.2 & 1 & 66.9 & 5.3 & 6.7 & 1. & 13.2 & 13.9 & 5.9 & 19.8 & 6.4 & 5.0 \\
\hline Czech R. & $\overline{009 / \mathrm{q}}$ & 77.3 & 2 & 80.0 & 1.3 & 10.7 & 0. & 12.5 & 4. & 2. & 7.4 & 6.6 & 2.7 \\
\hline Slovakia & $2008 / q$ & 77.4 & 2. & 80.3 & 1.2 & 11.0 & 0 & 12.2 & 6 & 1. & 7.5 & 9.3 & 2.2 \\
\hline Russia & $2008 / \mathrm{q}$ & 78.8 & 1.5 & 80.3 & 6.1 & 5. & 0 & 12.0 & 4 & 3 & 7.7 & 7.4 & 4.2 \\
\hline Romania & 2009/q1 & 78.0 & 1. & 79.6 & 5.1 & 5.9 & 0 & 11.8 & 5.5 & 3. & 8.6 & 6.7 & 2.9 \\
\hline Estonia & 2009/q1 & 78.0 & 2. & 80.2 & 3.2 & 6 & 0 & 9.8 & 6.8 & 3.1 & 9.9 & 10.3 & 4.2 \\
\hline Hungary & 2009/q1 & 71.6 & 1. & 72.6 & 2.6 & 6.2 & 0 & 9.4 & 12.4 & 5.6 & 18.0 & 9.7 & 2.4 \\
\hline Latvia & 2009/q2 & 69.4 & 1. & 71.2 & 3.7 & 3.6 & 0 & 8.0 & 13.9 & 6.8 & 20.7 & 17.0 & 5.9 \\
\hline Lithuania & 2009/q4 & 74.2 & 1.4 & 75.5 & 2.2 & 4.2 & 0.0 & 6.4 & 12. & 5.6 & 18.1 & 15.6 & 3.0 \\
\hline \multicolumn{14}{|c|}{ Western Europe } \\
\hline Ireland & 2009/q4 & 45.8 & 2.4 & 48.2 & 18.1 & 13.4 & 1.5 & 33.0 & 13.8 & 5.0 & 18.8 & 12.6 & 15.1 \\
\hline UK & $2008 / q 4$ & 67.8 & 2.5 & 70.3 & 9.6 & 11.0 & 1.1 & 21.7 & 6.0 & 2.0 & 8.0 & 6.2 & 5.2 \\
\hline Austria $^{a}$ & 2007/q3 & 73.7 & 2.4 & 76.1 & 8.5 & 9.9 & 1.3 & 19.7 & 2. & 1.6 & 4.2 & 4.3 & 3.4 \\
\hline Switzerland & $2008 / q 4$ & 79.1 & 2.4 & 81.5 & 1.9 & 11.5 & 0.3 & 13.7 & 3 & 0.9 & 4.7 & 4.0 & 1.8 \\
\hline Netherland & $2008 / q 4$ & 79.7 & 4.2 & 84.0 & 2.4 & 9.1 & 1.1 & 12.6 & 2.1 & 1.3 & 3.4 & 3.1 & 2.2 \\
\hline Germany & 2008/q4 & 75.4 & 4.5 & 79.9 & 1.6 & 10.1 & 0.2 & 11.9 & 5.9 & 2.3 & 8.2 & 7.1 & 2.5 \\
\hline Belgium & 2008/q4 & 74.9 & 4.2 & 79.1 & 1.6 & 8.4 & 0.5 & 10.5 & 5.4 & 5.1 & 10.5 & 7.2 & 2.4 \\
\hline France & 2008/q4 & 79.0 & 1.2 & 80.2 & 2.7 & 7.1 & 0.5 & 10.3 & 7.7 & 1.8 & 9.5 & 8.3 & 1.0 \\
\hline \multicolumn{14}{|c|}{ Northern Europe } \\
\hline Norway & 2008/q3 & 82.6 & 2.6 & 85.2 & 4.7 & 7.2 & 0.4 & 12.3 & 0 & 0.6 & 2.6 & 2.5 & 2.5 \\
\hline Denmark & 2008/q4 & 82.2 & 2. & 84.6 & 3.9 & 7.5 & 0.1 & 11.5 & 9 & 1.0 & 3.9 & 3.5 & 1.9 \\
\hline Finland & 2008/q4 & 80.0 & 2.9 & 82.9 & 0.9 & 10.1 & 0.2 & 11.2 & 3.7 & 2.2 & 5.9 & 6.2 & 1.0 \\
\hline eden & 200 & 84.6 & 2.8 & 87.4 & 0.8 & 7.1 & 0.3 & 8.2 & 3.5 & 1.1 & 4.6 & 6.3 & 1.2 \\
\hline
\end{tabular}

Notes: ${ }^{\text {a }}$ Results are based on round 4 of ESS. Results of round 4 were not available for Italy and Austria; the latest available results are presented instead. ' 'Core period' is the quarter during which most of the field work has been performed; it is given for the reference only; by contrast, LFS-based unemployment rate has been calculated as weighted average of quarterly unemployment rates for quarters covering the whole field work period. ${ }^{\mathrm{C}}$ Due to data limitations (only year but not month of the last job is known for non-employed respondents), the shares of non-employed who were recently informally employed (see the last column) are not perfectly comparable across countries. Average 'recent' period varies as follows: 10-16 months in the South, 1118 months in the East, 11-15 months in the West, and 10-12 months in the North. Experiments with the data show, however, that changing this period by few months do not change the results significantly.

Source: Calculation with ESS data. 
Table 4 Informal employees as percentage of all employees, by European region and worker category, 2008-2009

\begin{tabular}{|c|c|c|c|c|c|c|c|}
\hline & South & $E S, P T, G R$ & East & West & North & Total & $\begin{array}{c}\% \\
N \text { obs. }\end{array}$ \\
\hline Total & 21.1 & 14.2 & 5.3 & 7.1 & 2.7 & 8.6 & 26247 \\
\hline Male & 19.2 & 12.8 & 5.4 & 7.0 & 2.6 & 8.2 & 12839 \\
\hline Female & 22.9 & 15.6 & 5.1 & 7.2 & 2.7 & 8.9 & 13405 \\
\hline \multicolumn{8}{|l|}{ Education } \\
\hline Less than secondary & 20.9 & 14.9 & 9.0 & 12.9 & 5.3 & 14.5 & 5049 \\
\hline Secondary & 24.5 & 17.6 & 5.1 & 6.8 & 3.2 & 8.4 & 12758 \\
\hline Tertiary & 16.6 & 8.6 & 4.2 & 3.4 & 1.4 & 5.7 & 8407 \\
\hline Students (all levels) & 30.5 & 20.2 & 21.3 & 16.0 & 12.7 & 19.7 & 1000 \\
\hline \multicolumn{8}{|l|}{ Age } \\
\hline $15-24$ & 29.5 & 21.6 & 14.9 & 13.8 & 8.1 & 17.0 & 2378 \\
\hline $25-54$ & 18.5 & 12.9 & 4.1 & 5.6 & 1.9 & 7.1 & 19653 \\
\hline $55-64$ & 26.5 & 13.1 & 5.2 & 8.6 & 2.4 & 9.0 & 3673 \\
\hline $65+$ & 33.9 & 36.4 & 8.0 & 23.7 & 6.9 & 15.7 & 489 \\
\hline \multicolumn{8}{|l|}{ Origin } \\
\hline Native majority & 15.7 & 12.2 & 4.2 & 7.1 & 2.8 & 6.9 & 19999 \\
\hline Native minority & 30.3 & 16.1 & 10.7 & 6.0 & 1.8 & 14.0 & 1770 \\
\hline $2^{\text {nd }}$ generation immigrant & 31.1 & 14.4 & 6.7 & 6.2 & 2.1 & 12.6 & 2092 \\
\hline Immigrant: & & & & & & & 2386 \\
\hline Working rights due to nationality ${ }^{\mathrm{a}}$ & 30.0 & 16.5 & 6.5 & 8.7 & 1.9 & 15.0 & 1650 \\
\hline No working rights due to nationality & 33.5 & 33.7 & 5.9 & 6.0 & 0.0 & 14.3 & 736 \\
\hline From CEE of FSU & 37.1 & 55.4 & 7.1 & 11.9 & 1.4 & 18.9 & 1049 \\
\hline From developing countries & 23.6 & 16.2 & 1.9 & 6.8 & 0.0 & 13.0 & 728 \\
\hline From developed countries & 28.8 & 20.8 & 0.0 & 5.2 & 2.3 & 8.6 & 609 \\
\hline \multicolumn{8}{|l|}{ Occupation } \\
\hline Highly skilled non-manual & 17.2 & 8.6 & 3.0 & 3.9 & 1.2 & 5.1 & 10986 \\
\hline Low skilled non-manual & 20.9 & 12.4 & 6.8 & 9.0 & 3.8 & 10.7 & 6909 \\
\hline Skilled manual & 21.9 & 13.6 & 5.6 & 8.5 & 3.8 & 9.0 & 5479 \\
\hline Elementary & 30.3 & 28.6 & 9.7 & 14.6 & 8.0 & 16.8 & 2319 \\
\hline \multicolumn{8}{|c|}{ Establishment size } \\
\hline $1-9$ & 31.2 & 25.7 & 10.6 & 13.2 & 4.9 & 16.2 & 6501 \\
\hline $10-24$ & 15.5 & 9.5 & 5.5 & 7.7 & 2.6 & 7.8 & 5549 \\
\hline 25-99 & 16.5 & 4.1 & 2.5 & 5.7 & 1.4 & 5.5 & 6445 \\
\hline $100+$ & 14.9 & 6.3 & 1.7 & 2.7 & 1.9 & 4.1 & 6893 \\
\hline NA & 21.1 & 6.5 & 10.3 & 17.6 & 29.0 & 13.4 & 859 \\
\hline \multicolumn{8}{|c|}{ Economic activity } \\
\hline Agriculture \& Forestry & 31.1 & 27.7 & 7.1 & 14.3 & 5.6 & 13.3 & 623 \\
\hline Manufacturing and Mining & 15.8 & 9.5 & 3.1 & 5.1 & 2.1 & 5.6 & 4341 \\
\hline Construction & 27.1 & 19.7 & 11.4 & 10.0 & 5.5 & 13.7 & 1863 \\
\hline Trade \& Auto Repair & 24.5 & 13.9 & 7.7 & 9.1 & 3.3 & 11.0 & 3292 \\
\hline Hotels \& Restaurants & 29.7 & 22.1 & 10.4 & 22.2 & 6.1 & 19.7 & 996 \\
\hline Transport & 23.0 & 12.5 & 3.5 & 6.6 & 4.3 & 7.6 & 1271 \\
\hline Finances & 17.1 & 2.4 & 3.4 & 3.1 & 1.8 & 6.0 & 824 \\
\hline Business Services & 15.1 & 9.2 & 6.5 & 6.8 & 1.4 & 7.8 & 2243 \\
\hline Public utilities & 22.2 & 7.4 & 2.3 & 10.1 & 0.0 & 6.3 & 335 \\
\hline Post \& Telecom & 8.4 & 7.2 & 3.8 & 3.7 & 0.0 & 4.5 & 443 \\
\hline Public Administration & 14.5 & 5.4 & 2.6 & 4.3 & 1.1 & 6.1 & 2055 \\
\hline Education & 18.7 & 7.5 & 2.1 & 4.8 & 2.0 & 6.1 & 2644 \\
\hline Health \& Social Care & 10.8 & 9.1 & 2.1 & 4.8 & 1.9 & 4.1 & 2808 \\
\hline Personal \& HH Services & 39.5 & 38.6 & 8.3 & 13.3 & 5.2 & 17.7 & 1471 \\
\hline
\end{tabular}

Notes: For Italy and Austria, results refer to 2006 and 2007, respectively. Countries weighted equally (i.e. a respondent from any country is equally likely to be sampled. ${ }^{\text {a }}$ Country-specific (and year-specific) rules on free movement of labor within EU are taken into account. Source: Calculation with ESS data. 
Table 5 Dynamics of informal employment and unemployment in European countries, 2004-2009

\begin{tabular}{|c|c|c|c|c|c|c|c|c|}
\hline & \multicolumn{2}{|c|}{$\begin{array}{c}\text { Informal Dependent } \\
\text { Employment }\end{array}$} & \multicolumn{2}{|c|}{$\begin{array}{c}\text { Informal } \\
\text { Self-Employment }\end{array}$} & \multicolumn{2}{|c|}{$\begin{array}{l}\text { Total Unemployed } \\
\text { Willing to Work }\end{array}$} & \multicolumn{2}{|c|}{$\begin{array}{l}\text { LFS-Based } \\
\text { Unempl. Rate }\end{array}$} \\
\hline & 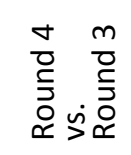 & 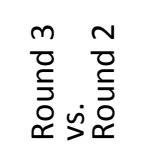 & 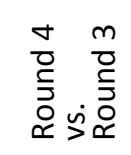 & 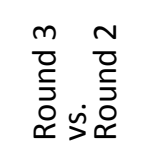 & 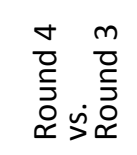 & 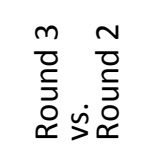 & 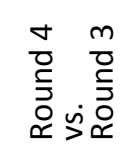 & 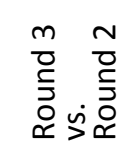 \\
\hline & \multicolumn{8}{|c|}{ Southern Europe } \\
\hline Cyprus & $-5.4^{*}$ & & 0.0 & & $-3.4^{* *}$ & & -0.5 & \\
\hline Greece $^{b}$ & -0.5 & & 0.7 & & $-2.7^{*}$ & & -0.9 & \\
\hline Portugal & 0.0 & $3.6^{* * *}$ & 1.5 & -2.5 & $1.1^{* * *}$ & $-1.4^{* * *}$ & 0.1 & 0.9 \\
\hline \multirow[t]{2}{*}{ Spain } & -0.6 & $1.0^{* * *}$ & -1.0 & 1.7 & $3.7^{* * *}$ & -1.8 & 4.7 & -1.8 \\
\hline & \multicolumn{8}{|c|}{ Eastern Europe } \\
\hline Poland & -0.2 & 0.9 & $4.2^{* *}$ & $-3.5^{* *}$ & $-2.7^{*}$ & $-5.8^{* * *}$ & -5.4 & -5.8 \\
\hline Ukraine & 0.2 & 0.5 & 1.1 & 2.0 & -3.0 & -2.1 & 2.7 & -1.9 \\
\hline Slovenia & $2.7^{* *}$ & -1.1 & 1.3 & -1.5 & $-6.3^{* * *}$ & $5.2^{* * *}$ & -1.3 & -0.9 \\
\hline Bulgaria & $-2.4^{* *}$ & & 0.5 & & -3.2 & & -2 & \\
\hline Czech R. ${ }^{\text {b }}$ & -0.8 & & 1.7 & & $-2.5^{* *}$ & & -1.6 & \\
\hline Slovakia & -1.0 & 0.3 & 1.6 & -1.3 & $-4.6^{* * *}$ & $-6.2^{* * *}$ & -2.6 & -5.4 \\
\hline Russia & 1.2 & & 0.7 & & 0.1 & & 0.8 & \\
\hline Estonia & -0.5 & $2.0^{* * *}$ & $1.8^{*}$ & $-1.6^{*}$ & $6.2^{* * *}$ & $-4.8^{* * *}$ & 4.9 & -3.4 \\
\hline Hungary & 0.6 & -1.2 & -1.1 & -0.9 & $7.5^{* * *}$ & 2.4 & 2.2 & 0.4 \\
\hline \multirow[t]{2}{*}{ Latvia } & $-2.4^{* * *}$ & & 0.3 & & $10.7^{* * *}$ & & 11 & \\
\hline & \multicolumn{8}{|c|}{ Western Europe } \\
\hline Ireland & $-6.9^{* * *}$ & -2.0 & -0.9 & 1.1 & $11.2^{* * *}$ & 1.7 & 8.1 & 0.1 \\
\hline UK & -0.4 & -2.3 & 1.5 & -1.0 & 1.2 & $-3.1^{* *}$ & 0.7 & 0.8 \\
\hline Austria & & 1.3 & & 0.4 & & $-3.6^{* * *}$ & & -0.9 \\
\hline Switzerland & -0.5 & 0.8 & -2.1 & 1.9 & 1.2 & -1.1 & 0.5 & -0.9 \\
\hline Netherlands & $-1.7^{* *}$ & -1.0 & $2.2^{*}$ & -0.6 & $-2.5^{* * *}$ & -0.6 & -0.9 & -1.1 \\
\hline Germany & 0.3 & -0.5 & 0.3 & 1.1 & $-3.8^{* * *}$ & -1.7 & -2.2 & -0.9 \\
\hline Belgium & 0.0 & -0.4 & -1.2 & -0.1 & -1.0 & -1.6 & -0.7 & -0.5 \\
\hline \multirow[t]{2}{*}{ France } & -1.1 & & 1.4 & & 0.1 & & -0.7 & \\
\hline & \multicolumn{8}{|c|}{ Northern Europe } \\
\hline Norway & -0.9 & 0.5 & $-2.1^{*}$ & -0.2 & -0.6 & $-2.9^{* * *}$ & 0.7 & -1.2 \\
\hline Denmark & $-3.9^{* * *}$ & $2.7^{* *}$ & 0.1 & 1.0 & 0.3 & $-4.2^{* * *}$ & -0.2 & -1.3 \\
\hline Finland & 0.4 & -0.1 & 0.6 & -0.6 & $-2.4^{* *}$ & -1.1 & -0.6 & -1.1 \\
\hline Sweden & 0.2 & 0.1 & -0.2 & -0.4 & $-1.5^{*}$ & -1.5 & 0.2 & -0.9 \\
\hline
\end{tabular}

Notes: ${ }^{\mathrm{a}}$ The table presents the changes in estimated prevalence of informal employment and unemployment between ESS rounds: Round 4 (2008-2009), Round 3 (2006-2007), Round 2 (2004-2005). ${ }^{\mathrm{b}}$ For Greece and the Czech R., Round 4 is compared to Round 2 (rather than to Round 3).

${ }_{*}^{* * *, * * *}$ - estimates significantly different from 0 at the $10 \%, 5 \%, 1 \%$ level, respectively (not shown for LFSbased unemployment rates).

Source: Calculation with ESS data. 
Table 6 Sectoral distribution of informal workers' main job, by European region and employment status. 2004-2009

Agriculture \&

Forestry

Manufacturing

Construction

Trade, Auto Repair,

Hotels \& Restaurants

Transport, finance,

\& business activities

Education, Health \&

Social Care, Public

Administration,

Utilities, Post \&

Communications

Community,

Personal \& Household

Services

NA

Total

N obs.
East

South

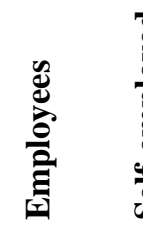

$\begin{array}{rr}5.4 & 1 \\ 14.7 & \end{array}$

13.0

$20.7 \quad 27$

$10.6 \quad 15.4$

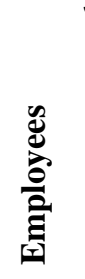

3.9

3.9
13.4

19.8

9.2

8.2

11.6

8.9

10.8

22.2

34.1
कृ

29.4

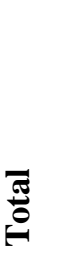

产

West

$13.3 \quad 1.7 \quad 15.6$

$1.0 \quad 14.2$

8.0

8.

11.7

North

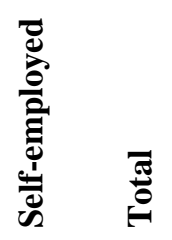

$11.1 \quad 3.8$

21.4

17.7

10.2

14.6

21.4
6.7

8.5

10.4

14.8

12.4

12.9

Notes: See Table 1 for definitions of informal employment. Columns 'Employees' and 'Self-employed' here correspond, respectively, to categories 5 and 3 defined in Table 1; column 'Total' includes also family workers. Countries are not weighted by population size. Design weights corrected for variation of sample size across countries in each round are applied (i.e., all respondents are assumed equally likely to be sampled; countries which did not participate in some rounds are, however, under-represented). Source: Calculation with ESS data.

Table 7 Perceived discrimination on grounds of race, ethnicity, religion, language, nationality, age or disability among formal and informal workers, by European region. 2004-2009

\begin{tabular}{lrrrrr} 
& \multicolumn{1}{c}{ South } & \multicolumn{1}{c}{ East } & \multicolumn{1}{c}{ West } & \multicolumn{1}{c}{ North } & \multicolumn{1}{c}{ Total } \\
[1] Formal Employees & 3.5 & 3.8 & 4.1 & 2.3 & 3.6 \\
[2] Informal Employees & 7.6 & 6.4 & 5.3 & 2.8 & 6.2 \\
[3] Informal Self-employed & 3.9 & 4.0 & 3.9 & 2.3 & 3.7 \\
& & & & & \\
$\quad$ [2]/[1] & 2.18 & 1.70 & 1.30 & 1.24 & 1.74 \\
t-test : [2] $=[1]$ & 0.000 & 0.002 & 0.057 & 0.540 & 0.000 \\
t-test : [3] = [1] & 0.505 & 0.638 & 0.749 & 0.970 & 0.609
\end{tabular}

Notes: Countries are not weighted by population size. Design weights corrected for variation of sample size across countries in each round are applied (i.e., all respondents are assumed equally likely to be sampled; countries which did not participate in some rounds are, however, under-represented).

Source: Calculation with ESS data. 
Table 8 Labor market status effects on perception of household's financial difficulties in European regions, 2004-2009. Population aged 15-74

Ordered probit coefficients

\begin{tabular}{|c|c|c|c|c|c|}
\hline & South & East & West-1 & West-2 & North \\
\hline $\begin{array}{c}\text { Employment status } \\
\text { (vs. formal employees) }\end{array}$ & & & & & \\
\hline Formal self-employment & $-0.518^{* * *}$ & $-0.640^{* * *}$ & $-0.308^{* * *}$ & $-0.318^{* * *}$ & -0.093 \\
\hline Informal self-employment & $-0.130^{* * *}$ & $-0.320^{* * *}$ & -0.018 & -0.067 & $0.090^{* *}$ \\
\hline Family workers & $-0.385^{* * *}$ & $-0.633^{* * *}$ & 0.016 & 0.230 & 0.237 \\
\hline Informal dependent employees & $0.169^{* * *}$ & $0.170^{* * *}$ & $0.127^{* * *}$ & $0.332^{* * *}$ & $0.195^{* * *}$ \\
\hline Unemployed willing to work & $0.723^{* * *}$ & $0.872^{* * *}$ & $0.908^{* * *}$ & $0.911^{* * *}$ & $0.906^{* * *}$ \\
\hline Other (inactive) & $0.089^{* * *}$ & $0.264^{* * *}$ & $0.254^{* * *}$ & $0.171^{* * *}$ & $0.493^{* * *}$ \\
\hline Other controls & $\begin{array}{c}\text { Gender, family status, children, age, age squared, education, country } \\
\text { and time fixed effects, parental background, ethnic/immigration }\end{array}$ \\
\hline origin, rural residence, economic activity of last employment, \\
\hline Pseudo R-sq. & \multicolumn{2}{|c|}{ disability status, household size (log) } \\
\hline N obs. & 0.1160 & 0.1435 & 0.0692 & 0.0913 & 0.1157 \\
\hline
\end{tabular}

Notes: South : ES, PT, IT, GR, CY, and IL; East : CZ, PL, SK, HU, EE, LV, BG, RO, SI, RU, and UA; North: DK, FI, NO, and SE; West -1: UK, IE, NL, and AT; West-2: DE, FR, BE, and CH.

Larger coefficients indicate larger perceived difficulties. $*, * *, * * *$ indicate that respective coefficient for the given employment status is significantly different from the coefficient for formal employees at $10 \%, 5 \%, 1 \%$ level, respectively (based on robust standard errors clustered on within-country region). Marginal effects are presented in Figure 7. Countries are not weighted by population size. Design weights corrected for variation of sample size across countries in each round are applied (i.e., all respondents are assumed equally likely to be sampled; countries which did not participate in some rounds are, however, under-represented).

Source: Calculation with ESS data. 
Table 9 Determinants of working without a contract, 2004-2009

(Mixed-effects logistic regression: Marginal effects)

\begin{tabular}{|c|c|c|c|c|c|c|c|c|c|}
\hline \multirow{2}{*}{$\begin{array}{r}\text { Country group } \\
\text { (\% employees } \\
\text { without a contract) }\end{array}$} & East -1 & East -2 & North & West -1 & West -2 & \multicolumn{2}{|c|}{ South -1 } & \multicolumn{2}{|c|}{$\begin{array}{l}\% \text { points } \\
\text { South }-2\end{array}$} \\
\hline & (5.14) & (5.07) & (3.16) & $(13.80)$ & (2.53) & (13.) & 14) & \multicolumn{2}{|c|}{ (33.15) } \\
\hline \multicolumn{10}{|l|}{$\begin{array}{l}\text { Education (vs. } \\
\text { Upper Secondary) }\end{array}$} \\
\hline Primary or less & $3.41 * * *$ & $\begin{array}{l}-0.77+ \\
\left(5.70^{* * *}\right) \times \mathrm{RO}\end{array}$ & $0.71 *$ & $4.70 * * *$ & 0.35 & 3.42 & $* * *$ & 10.57 & $* * *$ \\
\hline Tertiary & $-1.10 *$ & $\begin{array}{l}-2.73 * * *+ \\
(7.48 * * *) \times \mathrm{RO}\end{array}$ & $-1.32 * * *$ & $\begin{array}{l}-9.29 * * *+ \\
(5.20 * * *) \times \text { UK }\end{array}$ & $-0.94 * *$ & -3.97 & $* * *$ & -3.42 & $(*)$ \\
\hline Student & $3.24^{* * *}$ & $5.24^{* * *}$ & $2.70 \quad * * *$ & $10.30^{* * *}$ & $2.77^{* * *}$ & 3.69 & $*$ & 14.49 & $*$ \\
\hline \multicolumn{10}{|l|}{ Sector (vs. Industry) } \\
\hline Agriculture & $3.55 * * *$ & 2.63 & $2.01 * * *$ & $5.56 *$ & 0.19 & 14.90 & $* * *$ & -1.95 & \\
\hline $\begin{array}{l}\text { Construction, Trade, } \\
\text { Hospitality, Personal } \\
\text { \& Household Services }\end{array}$ & $4.11 * * *$ & $3.38 * * *$ & 0.67 & $3.89 * * *$ & 1.08 & 9.96 & $* * *$ & 5.76 & $*$ \\
\hline $\begin{array}{r}\text { Transport, Finance \& } \\
\text { Business Services } \\
\end{array}$ & 0.37 & $2.92 * * *$ & 0.15 & $-0.78(*)$ & 0.43 & 3.64 & $* *$ & -5.54 & $(*)$ \\
\hline Public Services & $-2.21 * * *$ & 1.03 & $-1.30 * *$ & \begin{tabular}{l|l|}
-2.58 & $*$ \\
\end{tabular} & 0.22 & 0.65 & & -8.42 & $* * *$ \\
\hline Age & $-0.48 * * *$ & $-0.74 * *$ & $-0.34 * * *$ & $-0.93 * * *$ & $-0.41 * * *$ & -0.19 & & -2.05 & $* * *$ \\
\hline Age-squared/100 & $0.53 * * *$ & $0.77 * *$ & $0.44 * * *$ & $1.20 * * *$ & $0.53 * * *$ & 0.44 & $* *$ & 2.35 & $* * *$ \\
\hline Female & $-0.86 *$ & $\begin{array}{l}1.72^{* *}- \\
\left(3.91^{* * *}\right) \times \mathrm{HU}\end{array}$ & 0.21 & $1.69\left(^{*}\right)$ & $\begin{array}{l}-0.64+\left(1.53^{* *}\right) \\
\times(\mathrm{DE}+\mathrm{CH})\end{array}$ & 3.42 & $* * *$ & 3.82 & $*$ \\
\hline With Partner & $-2.15 * * *$ & 0.17 & -0.14 & -0.17 & $-1.24 * *$ & -4.13 & $* * *$ & 2.22 & \\
\hline Female*With Partn. & 0.92 & & $-1.43 *$ & -1.92 & $1.17^{*}$ & 4.30 & $* *$ & & \\
\hline With Children & 0.47 & $-4.05 * * *$ & -0.42 & -0.26 & -0.46 & -0.01 & & 3.04 & \\
\hline Female*With Children & -0.95 & & 0.86 & -1.00 & 0.90 & -1.62 & & -6.50 & $*$ \\
\hline Rural & $0.97 * * *$ & -0.78 & 0.41 & 0.53 & $0.55 *$ & $\begin{array}{r}2.67^{*} \\
\times(-7.5\end{array}$ & $\begin{array}{l}*+\mathrm{IL} \\
4 * * *)\end{array}$ & -0.01 & \\
\hline $\begin{array}{l}\text { Minority } \\
\text { (local born) }\end{array}$ & $2.06 * * *$ & -1.16 & -1.59 & -1.19 & 0.13 & $\begin{array}{l}2.42+\mathrm{IL} \\
\left(26.8^{* *}\right.\end{array}$ & & 2.23 & \\
\hline $\begin{array}{l}\text { One parent } \\
\text { Immigrant }\end{array}$ & $1.02 *$ & 1.62 & -0.43 & -1.48 & -0.06 & $\begin{array}{l}-5.90+ \\
\left(30.20^{*}\right.\end{array}$ & $\begin{array}{l}\text { IL } \times \\
* *)\end{array}$ & 12.75 & $*$ \\
\hline $\begin{array}{l}\text { Both parents } \\
\text { Immigrants }\end{array}$ & $1.85 * *$ & $-3.83 * *$ & -3.82 & 3.03 & -0.73 & $\begin{array}{l}-1.23+ \\
(23.74 *\end{array}$ & $\begin{array}{l}\text { IL } \times \\
* *)\end{array}$ & -12.0 & \\
\hline $\begin{array}{l}\text { Immigrant, working } \\
\text { right by nationality }\end{array}$ & $1.38(*)$ & -0.28 & -0.67 & 1.68 & 0.41 & $\begin{array}{l}5.52 * *_{+} \\
(14.96 *\end{array}$ & & 0.16 & \\
\hline Other immigrants & $2.13 * *$ & & 0.04 & $5.59 * * *$ & -1.20 & $12.69 * *$ & & 21.38 & $* * *$ \\
\hline Return migrant & $1.84 * * *$ & $2.28\left(^{*}\right)$ & 0.40 & -0.62 & -0.96 & -0.48 & & 0.29 & \\
\hline Disabled & $0.65(*)$ & 0.63 & $0.98 * * *$ & $1.63 *$ & 0.37 & 2.89 & $* *$ & -0.57 & \\
\hline Other controls & Country a & and year fixe & $\begin{array}{l}\text { effects; } M \\
\text { tus when as }\end{array}$ & $\begin{array}{l}\text { ther's highest } \\
\text { ed } 14 \text {; IE*age }\end{array}$ & $\begin{array}{l}\text { completed edu } \\
\text { IE*age-sq. (V }\end{array}$ & $\begin{array}{l}\text { estion le } \\
\text { est }\end{array}$ & vel; P & rents' v & work \\
\hline Log L & -3089.18 & - & - & -3054.65 & -1154.65 & -1749 & .56 & -1471 & 1.28 \\
\hline \# obs. [\# countries] & $17724[9]$ & $4357[3]$ & $11389[4]$ & $9601[4]$ & $10745[4]$ & 6079 & & 2815 & {$[3]$} \\
\hline \# regions & 118 & 27 & 24 & 64 & 34 & 19 & & 37 & \\
\hline Random effects s. d. & $0.2529 * * *$ & - & - & $0.1032 * *$ & $0.3479 * * *$ & 0.3829 & $* * *$ & 0.526 & $6 * * *$ \\
\hline LR test vs. logistic reg. & $\mathrm{P}=0.0025$ & - & - & $P=0.1146$ & $P=0.0082$ & $P=0.0$ & 000 & $P=0 . C$ & 0000 \\
\hline
\end{tabular}

Notes: East-1: CZ, PL, SK, EE, LV, LT, BG, RU, UA; East-2: HU, RO, SI; North: DK, FI, NO, SE; West-1: UK, IE, NL, and AT; West-2: DE, FR, BE, and CH; South-1: ES, PT, and IL; South-2: IT, GR, CY. The models include region-level random effects. For East-2 and North, these effects are integrated over the sample, i.e. population-averaged models estimated by the GEE method are presented. "Regions" are NUTS level 1 for DE, ES, FR and UK; NUTS level 2 for the Nordic countries, IE, CH, CZ, HU, PL, SK, RO, PT, GR, and IL; NUTS level 3 for the Baltic countries, NL, BG and SI; 10 federal regions for Russia, and 26 [oblast level] regions for Ukraine. Marginal effects are based on fixed parts of the models and conditional on working as employee (i.e. not corrected for selection into paid employment). $(*), *, * *, * * *-$ marginal effects significantly different from zero at $12 \%$, $10 \%, 5 \%, 1 \%$ level, respectively. Source: Calculation with ESS data. 
Annex Measurement issues

Table A1 Legal requirements on employee contracts in European countries

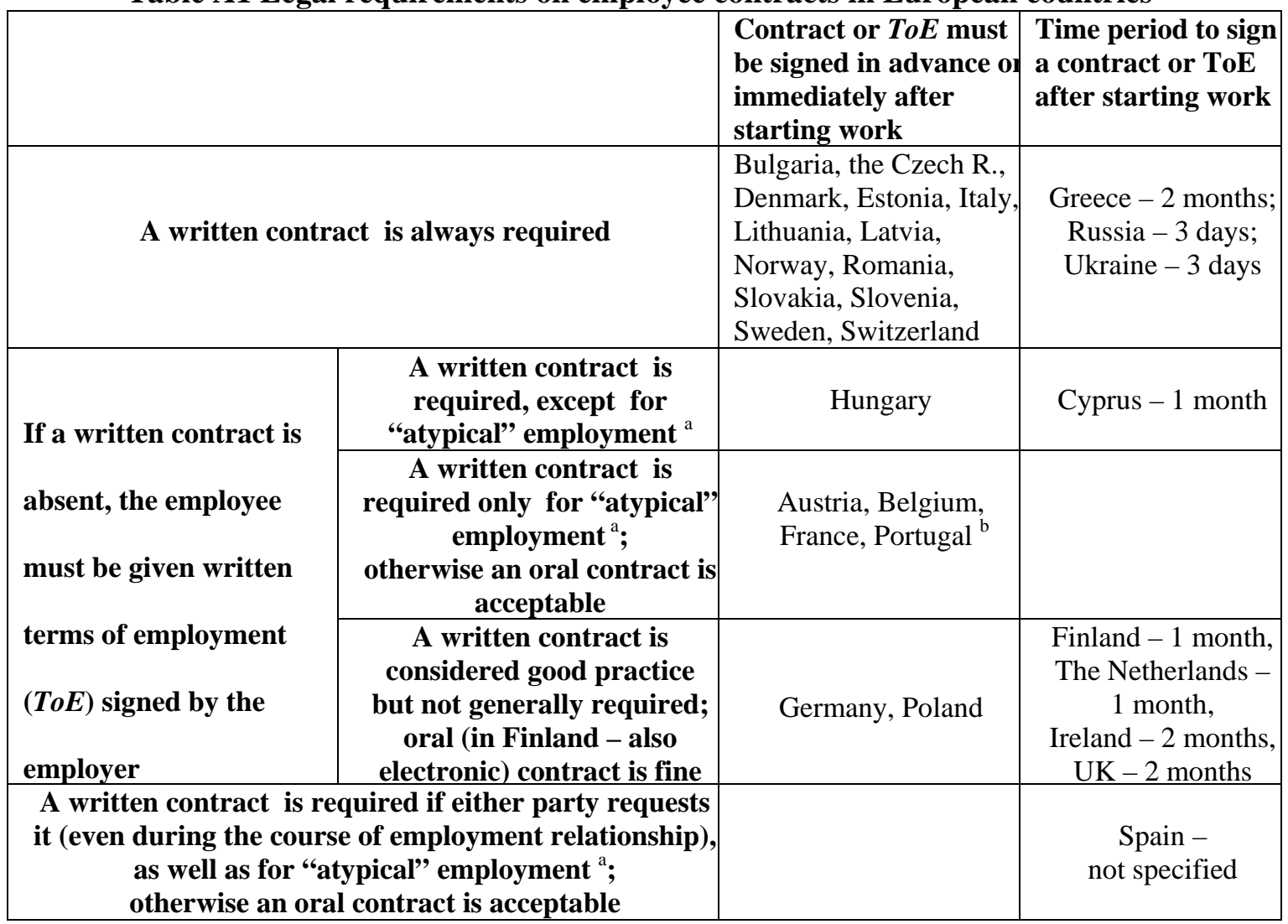

Notes: In most countries, having a written contract is considered good practice even when it is not required by the law. " "Atypical” employment include: Apprenticeship; Fixed-term contract or contract for specific work; Seasonal work; Replacement contract; Part-time contract; Contract employing a domestic worker.

${ }^{\mathrm{b}}$ In Portugal, very short-term contracts (as well as indefinite ones) might be oral. Source: EURES (2011).

Table A2 Employees' responses on European Social Survey question on contract type depending on presence of the answer 'no contract' (selected countries)

ESS round 1 (2002-2003)

ESS rounds 2-4 (2004-2009)

Employees not responding on the question on contract type (answer 'no contract' not offered)
Employees without a contract or not responding on the question on contract type $\min \max$ average $\%$ of all employees

$\begin{array}{lcccc}\text { Slovenia } & 2.3 & 4.5 & 7.7 & 6.0 \\ \text { Poland } & 1.2 & 5.4 & 6.0 & 5.8 \\ \text { Austria } & 2.8 & 9.0 & 10.3 & 9.7 \\ \text { Netherlands } & 1.4 & 6.2 & 5.0 & 2.9 \\ \text { The United Kingdom } & 2.6 & 16.2 & 12.4 & 12.4 \\ \text { Denmark } & 0.5 & 6.3 & 9.1 & 4.5 \\ \text { Portugal } & 1.0 & 5.8 & 10.5 & 10.8\end{array}$

Notes: In all rounds, answers "Contract of unlimited duration", "Contract of limited duration", and "Don't know" were offered. In addition, answer "No contract" was offered in rounds 2-4. Source: Calculation with ESS data. 
Table A3 Prevalence of informal employment in European countries: ESS results compared with other sources

\begin{tabular}{|c|c|c|c|c|c|c|c|}
\hline & \multicolumn{4}{|c|}{$\begin{array}{l}\text { (Informal employees) / } \\
\text { (All employees) }\end{array}$} & \multicolumn{3}{|c|}{$\begin{array}{l}\text { (Informally employed) / } \\
\text { (All employed) }\end{array}$} \\
\hline & \multicolumn{2}{|c|}{$\begin{array}{c}\text { Fourth European } \\
\text { Working Conditions } \\
\text { Survey (EWCS), } 2005\end{array}$} & \multicolumn{2}{|c|}{ European Social Survey } & \multirow{2}{*}{$\begin{array}{r}\text { EWCS } \\
2005\end{array}$} & \multicolumn{2}{|c|}{$\begin{array}{c}\text { European } \\
\text { Social Survey }\end{array}$} \\
\hline & $\begin{array}{c}\text { No } \\
\text { contract }\end{array}$ & $\begin{array}{l}\text { No contract } \\
\text { or no answer }\end{array}$ & \multicolumn{2}{|c|}{$\begin{array}{l}\text { No contract or no answer } \\
\text { to the contract question }\end{array}$} & & $\begin{array}{l}2004 / \\
2005\end{array}$ & $\begin{array}{l}2006 / \\
2007\end{array}$ \\
\hline & 1 & 2 & 3 & 4 & 5 & 6 & 7 \\
\hline Cyprus & 41.5 & 41.5 & & 56.8 & 50.2 & & 63.0 \\
\hline Greece & 26 & 27.3 & 35.4 & & 46.1 & 55.9 & \\
\hline Ireland & 27.7 & 28.4 & 34.9 & 33.8 & 38.0 & 43.7 & 43.5 \\
\hline Romania & 6.8 & 9.2 & & $6.1^{\mathrm{a}}$ & 31.3 & & \\
\hline Italy & 6.1 & 6.4 & & 4.8 & 28.1 & & 26.4 \\
\hline Portugal & 7 & 9.2 & 5.8 & 10.6 & 25.4 & 22.9 & 23.9 \\
\hline UK & 14.1 & 17 & 16.3 & 12.4 & 25.2 & 26.6 & 22.2 \\
\hline Poland & 5.8 & 6.5 & 5.4 & 5.9 & 24.7 & 24.9 & 20.2 \\
\hline Spain & 8.2 & 8.6 & 5.5 & 6.8 & 22.4 & 19.4 & 21.9 \\
\hline Austria & 8.6 & 14.9 & 9.0 & 10.3 & 22.0 & 19.5 & 20.6 \\
\hline Bulgaria & 6.2 & 8.1 & & 11.3 & 19.0 & & 19.7 \\
\hline Lithuania & 5.3 & 7.0 & & $3.0^{\mathrm{a}}$ & 18.8 & & \\
\hline Slovenia & 9.4 & 9.7 & 5.7 & 4.5 & 17.3 & 14.2 & 11.9 \\
\hline Switzerland & 2.8 & 3.1 & 2.1 & 3.1 & 15.1 & 14.3 & 17 \\
\hline Hungary & 4.4 & 4.4 & 4.1 & 2.6 & 15.0 & 13.1 & 11.1 \\
\hline Denmark & 10.3 & 10.5 & 6.3 & 9.1 & 14.2 & 12.6 & 15.9 \\
\hline Belgium & 2.5 & 3.4 & 2.7 & 2.1 & 13.2 & 14.0 & 13.1 \\
\hline Czech R. & 0.8 & 1.3 & 2.7 & & 12.9 & 13.2 & \\
\hline Estonia & 5.1 & 6.1 & 2.1 & 4.2 & 12.4 & 8.9 & 8.8 \\
\hline France & 3.9 & 4.3 & & 4.5 & 12.4 & & 11.1 \\
\hline Finland & 2.2 & 2.6 & 0.8 & 0.7 & 12.4 & 12.0 & 11.1 \\
\hline Slovakia & 1.3 & 1.8 & 2.8 & 2.9 & 12.1 & 15.5 & 13.2 \\
\hline Latvia & 5.4 & 6.3 & & 7.2 & 11.7 & & 11.2 \\
\hline Germany & 3.7 & 4.3 & 2.5 & 1.8 & 9.8 & 12.4 & 12.8 \\
\hline Norway & 2.1 & 2.5 & 6.2 & 6.5 & 9.8 & 15.9 & 15.7 \\
\hline Netherlands & 2.1 & 2.6 & 6.2 & 5.0 & 8.6 & 14.6 & 12.9 \\
\hline Sweden & 0.2 & 1.7 & 0.5 & 0.7 & 7.5 & 9.1 & 8.7 \\
\hline & Other surve & & ESS & ESS & & & \\
\hline & No contrac & Year & $2006 / 2007$ & 2008/2009 & & & \\
\hline Latvia $^{\text {b }}$ & 9.5 & $2006 / 2007$ & 7.2 & & & & \\
\hline Russia $^{c}$ & 11.0 & 2009 & & 7.2 & & & \\
\hline Bulgaria $^{\mathrm{d}}$ & 8.0 & 2009/2010 & & 7.5 & & & \\
\hline
\end{tabular}

Notes: Empty cells: data not available. Best matches between EWCS (col. 1 or 2) and ESS (col. 3 or 4) on work without contract are shown in bold. The EWCS-2005 total informality rate (col. 5) is very close either to both ESS-2004 and ESS-2006 rates (col. 6-7) or at least to one of them for most countries.

Employee sub-sample size used for calculations with EWCS data varies between 790 and 970, except for Cyprus (484), Slovenia, Estonia and Greece (540 to 640). Sub-sample size used for calculations with ESS data varies from 740 to 1200 employees, except for Cyprus ( 400), Italy (500), Bulgaria, Hungary, Slovenia and Poland (550 to 690). Total sample size is in most cases about 1000 for EWCS and between 1500 and 2400 for ESS. ${ }^{a}$ Romanian ESS data refer to 2008, whilst Lithuanian ESS data refer to 2009. Hence, lower informality rates than in EWCS-2005 are consistent with the fact that work without contract tends to be less prevalent during the recession (see Section 2.5). Sources: Calculation with ESS data and with data of European Foundation for the Improvement of Living and Working Conditions (2007). ${ }^{\mathrm{b}}$ Own calculations with the data of survey of economically active population aged 15-65 conducted for the project „Specific problems of the labour market in Latvia and its regions" of the National Program of Labor Market Studies, N=9306. ${ }^{\text {c }}$ Slonimczyk (2011: Table 5), based on Special Supplement to Russian Longitudinal Monitoring Survey. ${ }^{\mathrm{d}}$ Survey of $\mathrm{N}=6337$ employees conducted by Bulgarian Chamber of Commerce and Industry reported by Novinite (2011). 


\section{Proportion of informal employment in the labor force of European countries 2004-2009, by region}

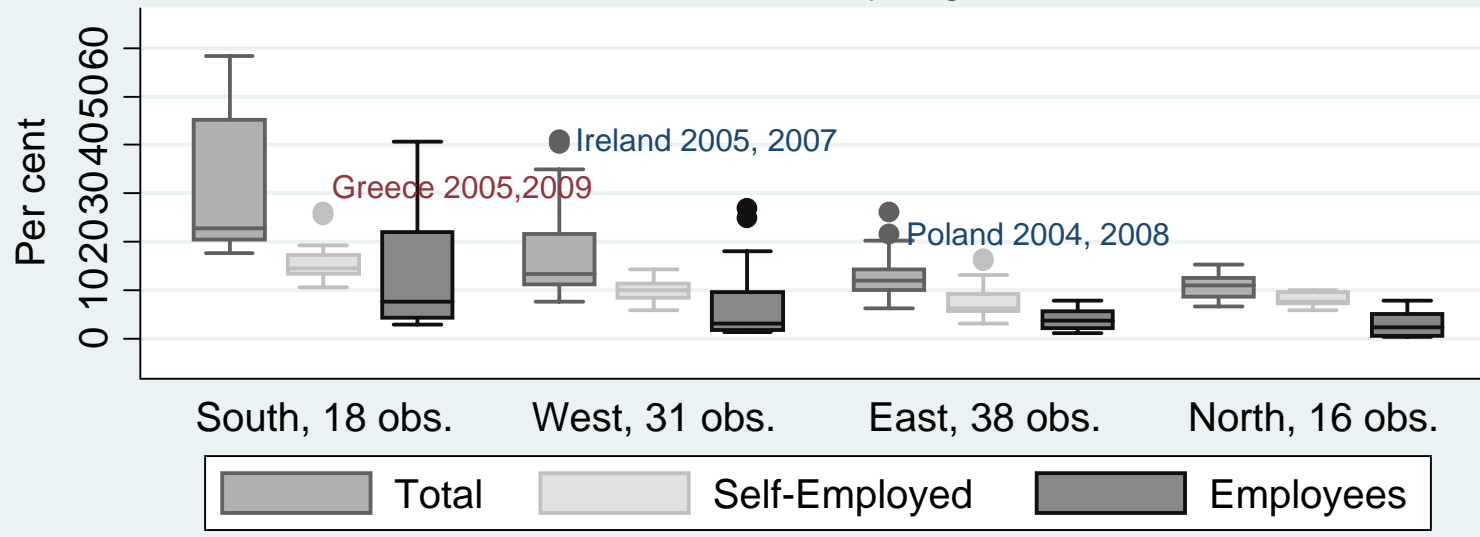

Based on rounds 2-4 of European Social Survey and the Fourth European Working Conditions Survey (2005) Countries (\# obs.) by region, sorted descending by average prevalence of total informal employment:

South - Cyprus (3), Greece (3), Malta (1), Israel (1), Italy (2), Portugal (4), Spain (4)

West - Ireland (4), UK (4), Austria (3), Switzerland (3), Belgium (4), Netherlands (4), Germany (4), France (3)

East - Poland (4), Romania (2), Bulgaria (3), Slovenia (4), Ukraine (3), Czech R. (3),

Lithuania (2), Slovakia (4), Hungary (4), Russia (2), Estonia (4), Latvia (3)

North - Denmark (4), Norway (4), Finland (4), Sweden (4)

Informal employment $=$ employees without contracts + non-professional self-employed without employees + + employers with $<=5$ employees

Labor force extended to include discouraged workers

EWCS data amended with unemployment and discouragement data from EU LFS 2005/Q4

Source: Calculation with ESS and EWCS data

Figure A1 Variation in size of total, dependent and own-account informal employment in countries of Southern, Western, Eastern, and Northern Europe. 2004-2009 